\title{
Behavior in All-Pay Auctions with Ties
}

\author{
Alan Gelder ${ }^{\mathrm{a}}$, Dan Kovenock ${ }^{\mathrm{a}}$, Roman Sheremeta ${ }^{\mathrm{a}, \mathrm{b}}$ \\ ${ }^{a}$ Economic Science Institute, Chapman University, Orange, CA 92866, USA \\ ${ }^{b}$ Department of Economics, Weatherhead School of Management, Case Western Reserve \\ University, Cleveland, OH, USA
}

\begin{abstract}
Despite the wide occurrence of ties in a variety of contest settings, the strategic interaction that arises when ties are treated as viable outcomes has received little attention. Building on recent theoretical work, we experimentally examine an extension of the canonical two-player all-pay auction in which a tie occurs unless one player's bid exceeds the other's by some critical threshold. In the event of a tie, each player receives an identical fraction of the prize. For the case where players receive one-half of the prize when they tie, we find that players' expenditures are non-monotonic in the threshold required for victory. Moreover, for certain positive thresholds, expenditures may even be higher than under the standard all-pay auction. We also find that decreasing the fraction of the prize players receive for tying may either increase or decrease total expenditures. In accordance with theory, the effect depends upon the threshold.
\end{abstract}

Keywords: All-pay auction, contest, tie, draw, bid differential, experiment JEL: C72, C92, D44, D72, D74

\section{Introduction}

Impasse, status quo, stalemate, gridlock, draw: each is essentially a tie. The variety of settings in which ties commonly occur is reflected by the nuances associated with these terms. There may be gridlock in a legislature or a jury may be at an impasse. Policy debates attempt to shift the status quo in one direction or another. Marketing campaigns are similar, but with the status quo posed in terms of existing brand loyalty. Military operations on the battlefield may culminate in a stalemate, and the notion of a tie or draw is well founded in the sporting arena. Settings like these, where competition is costly and the outcome is a function of the players' out-

Email addresses: gelder@chapman.edu (Alan Gelder), kovenock@chapman.edu (Dan Kovenock), roman.sheremeta@case.edu (Roman Sheremeta) 
lays, have long been modeled as contests - but predominantly in a binary win-loss paradigm. Strategically, however, this paradigm is not rich enough to adequately capture the twofold margins of competition between losing versus tying and tying versus winning.

The all-pay auction in particular has become a canonical workhorse in the study of contests, and yet the treatment of ties in its standard form is limited to knife-edge events. ${ }^{1}$ There, players submit bids simultaneously, the highest bidder wins, and (as the name suggests) all players pay the cost of their own bid. As such, it is a model of cutthroat competition in sunk expenditures. Equilibrium generally requires nondegenerate mixed strategies and ties are relegated to the off chance that the top two bids are precisely the same - a zero probability event in equilibrium. Important exceptions to this knife-edge property of ties arise in the case of all-pay auctions in which strategy spaces are constrained in some way, such as the assumption of a discrete strategy space or a continuous strategy space but with caps on bids. In each of these cases ties may arise with positive probability, depending on the assumptions made. See, for instance, Bouckaert et al.(1992), Baye et al. (1994), and Cohen and Sela (2007) for treatments of all-pay auctions with a discrete strategy space and Che and Gale (1998) and Szech (2015) for treatments of the all-pay auction with a continuous strategy space and a cap on bids.

Gelder et al. (2015) present a theoretical basis for extending the standard all-pay auction with a continuous strategy space to the study of ties. Specifically, they characterize the set of Nash equilibria in the symmetric two-player complete information setting where a tie occurs if neither player outbids the other by strictly more

\footnotetext{
${ }^{1}$ Ties have previously been addressed in other canonical contest models: the logit-type contest (Tullock, 1980, and Rosen, 1986) and the rank-order tournament (Lazear and Rosen, 1981). Blavatskyy (2010) generalizes the axiomatization of logit-type contests by Skaperdas (1996) and Clark and Riis (1998) to incorporate ties. Jia (2012) examines the nature of pure strategy equilibrium in a set of models in which performance is determined by stochastic shocks to players' efforts. These models generate Blavatskyy's logit-type contest success function and other modifications of logit-type models as special cases. Yildizparlak (2013, 2015) introduces a contest success function incorporating ties that generalizes the logit form and provides sufficient conditions for a symmetric and unique Nash equilibrium. Ties in the context of rank-order tournament models have been examined as far back as Nalebuff and Stiglitz (1983), in the context of a model of competitive principals and risk averse agents. They introduce a minimum distance or "gap" by which the best performance must beat the second best in order to induce a winner. They then demonstrate that performance in a symmetric pure strategy equilibrium may be improved if such a gap is incorporated within the tournament incentives. Extensions of the analysis of such tie gaps in the context of the pure strategy equilibria of the Lazear-Rosen (1981) model include Eden (2006) and Imhof and Kräkel $(2014,2015)$.
} 
than a given amount ${ }^{2}$ When players do tie, each receives an identical fraction of the prize. Thus ties are defined along two dimensions: the threshold required for victory, and the value of tying relative to winning and losing. Movement in either dimension alters the incentives players have for attempting to tie versus attempting to win.

In this article, we experimentally examine strategic behavior in this adaptation of the symmetric all-pay auction by varying both the value of a tie and also the size of the threshold that differentiates a win from a tie. We refer to these parameters as the tie prize and the tie margin. Specifically, we examine all-pay auctions in which twoplayers simultaneously place bids. If the higher bidder wins by strictly more than the tie margin $\delta \geq 0$ then he receives a winning prize of value $v=100$ and the low bidder receives a prize of 0 . If the difference between the two bids is less than or equal to the tie margin $\delta$, a tie arises and each player earns the tie prize of $\beta v<v$. We examine six treatments $(\beta v, \delta) \in\{(50,0),(50,10),(50,25),(50,40),(33,25),(33,40)\}$, utilizing tie prizes of 50 and 33 and tie margins corresponding to 0 (the standard all-pay auction), 10, 25, and 40.3 Over this range of parameter values, Nash equilibria are exclusively in non-degenerate mixed strategies, with gaps arising in the supports of the equilibrium distributions for some parameter configurations.

Our experimental results suggest that the twofold margins of competition arising from the inclusion of ties in the all-pay auction lead to both novel and interesting behavior. First, when the total prize value is fixed, so that the tie prize is exactly 50 , the sum of players' bids (which we term revenue) is non-monotonic in the tie margin $4^{4}$ Moreover, contrary to theoretical predictions, certain positive tie margins may actually generate more revenue than the standard all-pay auction. Across these treatments, a tie margin of 25 generates the highest revenue whereas a tie margin of 40 generates the lowest. The comparison between the treatments with tie margins of 0 and 10 yields no clear revenue ranking.

\footnotetext{
${ }^{2}$ See also Stong (2014) for preliminary results on an analysis of ties in an all-pay auction with incomplete information and Konrad and Kovenock (2014) for an analysis of ties (which they term a "status quo" outcome) in a model with complete information in which the probability of a tie is one unless some threshold bid is met or surpassed by one of the bidders. Otherwise, the probability of a tie is a fixed constant between zero and one.

${ }^{3}$ Since the differential between the winning and losing prizes is 100 , both the tie margins and tie prizes may be thought of in terms of percentages of the differential between the winning and losing prizes.

${ }^{4}$ The use of the term revenue stems from the literature on winner-pay auctions. However, since the all-pay auction is a model of costly sunk expenditures (e.g. lobbying costs, litigation fees, effort in a sporting match, etc.), revenue can be thought of as the collective dissipation of costly resources.
} 
If we hold the tie margin fixed across treatments and increase the tie prize, consistent with the theoretical prediction, we find that revenue may either increase or decrease. For a tie margin of 25 , a tie prize of 50 generates greater revenue than a tie prize of 33 . On the other hand, for a tie margin of 40, a tie prize of 50 generates less revenue than a tie prize of $33 .^{5}$

We also examine the time path of revenue over the thirty periods of our experiment. Most treatments feature revenue that increases in early periods and then tapers off. This pattern is quite strong in the treatments with tie margins of 0,10 , and 25 , where overdissipation of the prize emerges in a range of early periods, but underdissipation arises thereafter. In these treatments, a type of "shakeout" occurs, with players bidding quite aggressively and escalating over the early periods until some give in and bid more passively. For the treatments with a tie margin of 40, revenue in the initial few periods is at or near its peak, and underdissipation occurs over the whole course of the thirty periods. Despite these differences in the revenue paths within each treatment, the ranking of the treatments by revenue remains fairly constant over time.

Because our treatment with a tie prize of 50 and a tie margin of 0 is the standard all-pay auction, our work also contributes to the study of the standard all-pay auction in the absence of ties. Our results in this treatment are consistent with earlier papers on two player symmetric all-pay auctions (see Potters et al., 1998, and Ernst and Thöni, 2013) which find point estimates for revenue below, but not statistically different from, the theoretical prediction of exactly full dissipation of the prize. $\sqrt{6}$ This provides further support for the view that in the type of cutthroat com-

\footnotetext{
${ }^{5}$ Decreasing the tie prize to 33 makes the size of the purse conditional on the outcome of the contest. These results hold both in terms of revenue, as well as in terms of the auctioneer's profits (i.e. the sum of bids minus the value of any prizes players receive).

${ }^{6}$ However, our experimental procedures differ from previous studies. Subjects in our experiment participate in only one treatment and each treatment employs a random matching protocol over thirty periods of play in which players are provided their own past histories of play. We also allow players to place bids between 0 and 120 inclusive, with up to one decimal place, for a winning prize of $\mathrm{v}=100$. Potters et al.'s (1998) treatment of the two-player symmetric all-pay auction differs from our own in that they have a very coarse discrete strategy space of bids corresponding to integers between 0 and 15 for a prize of 13. Ernst and Thöni (2013) employ two separate treatments, each with ten periods of play. In one, there is a partners matching protocol in which each pair of contestants is fixed for the ten periods and information about previous bids and outcomes are provided in each period. In the other, subjects are randomly matched over the ten periods and are not provided information about the outcomes of previous contests. It is the former treatment that finds a point estimate for revenue below, but not statistically different from, the
} 
petition represented by the all-pay auction, the high degree of overdissipation that occurs in experiments with four or more players (see Davis and Reilly, 1998, Gneezy and Smorodinsky, 2006, and Lugovskyy et al., 2010) does not arise with two players.

To our knowledge the only experimental papers explicitly focusing on ties in the context of the all-pay auction with complete information assume either a potentially binding cap on bids, so that players may want to tie at the cap, or a relatively coarse discrete strategy space, so that the equilibrium probability of actually choosing the exact same bid is nonnegligible. Llorente-Saguer et al. (2015) is an example of the former, which experimentally implements Szech's (2015) extension of the Che and Gale (1998) model to examine the interaction between a potentially binding cap on bids and the choice of a tie-breaking rule. Cohen et al. (2012) is an example of the latter, which experimentally implements an all-pay auction with a discrete strategy space as in Bouckaert et al. (1992), Baye et al. (1994), and Cohen and Sela (2007).7 Amaldoss (2000), Amaldoss and Jain (2002), and Otsubo (2013) investigate models with both a relatively coarse discrete strategy space and a potentially binding cap on bids.

In Section 2, we introduce the theoretical model of the all-pay auction with ties and summarize its equilibrium properties. Section 3 presents the experimental design and Section 4 provides the results of the experiment. Section 5 concludes.

theoretical prediction. Fehr and Schmid (2011) and Chen et al. (2015) also examine two player allpay auctions. In the former, in contrast to our experiment, players value the prize asymmetrically. In the latter, play is one shot, and a coarse grid of 21 bids for a prize of $10 \mathrm{CNY}$ is utilized.

${ }^{7}$ Although our paper shares some similarities with Cohen et al. (2012) in that they also vary the tie prize, it differs from theirs along several important dimensions. Procedurally, there are distinct differences. In terms of the strategy space, we use a fine mesh with bid increments of 0.1 up to a budget of 120, in an auction with a winning prize worth 100. In contrast, Cohen et al. employ a coarse strategy space allowing nonnegative integer bids up to a budget of 30 New Israeli Shekels (NIS) for a winning prize also equal to 30 NIS. Also, in our study, 432 subjects play one of six treatments for thirty periods in a random matching protocol, whereas in Cohen et al., 79 subjects simultaneously play four separate tie prize treatments in a one-shot fashion by filling out a single menu of bids. More importantly, our paper differs substantially in terms of the equilibrium properties of the theoretical benchmarks and the qualitative nature of the experimental results. Although Cohen et al. experimentally vary the tie prize, their focus is on the perception of fairness, and they hypothesize that lower tie prizes will be viewed as unfair and lead to lower bids. They find that a "fair" tie prize of one-half the winning prize yields higher average bids than a tie prize of one-third the winning prize. Cohen et al. also vary the tie margin from 0 to 3 NIS (corresponding to $10 \%$ of the value of the winning prize), and find that such an increase in the tie margin increases average bids for all treatment values of the tie prize. In contrast, both our theoretical benchmark and our data indicate that changes in either the tie prize or the tie margin may either increase or decrease average bids. 


\section{Theory}

The two-player all-pay auction with ties extends the standard all-pay auction by requiring players to outbid their opponent by strictly more than $\delta \geq 0$ in order to win a prize of $v>0$. Otherwise, players tie and each receives $\beta v$ where $\beta \in$ $[0,1]$. We refer to $\delta$ as the tie margin and $\beta v$ as the tie prize. Players submit bids simultaneously where the bids have a unit cost, are paid upfront, and are nonrefundable. Formally, player $i$ chooses a bid $x_{i} \in \mathbb{R}_{+}$to maximize:

$$
\max _{x_{i}} p\left(x_{i}, x_{-i}\right) v-x_{i}
$$

where,

$$
p\left(x_{i}, x_{-i}\right)= \begin{cases}1 & \text { if } \quad x_{i}-x_{-i}>\delta \\ \beta & \text { if }\left|x_{i}-x_{-i}\right| \leq \delta \\ 0 & \text { if } \quad x_{-i}-x_{i}>\delta\end{cases}
$$

Gelder et al. (2015) characterize the full set of Nash equilibria for all $\delta \geq 0$ and $\beta \in[0,1]$. In order to place our experiment in the context of the full parameter space, we provide a brief overview of several key results. We then identify the equilibrium properties of the six specific parameter combinations used in our experiment.

The full $(\beta, \delta)$ parameter space can be broken down into four principle regions. These four regions, together with the location of the six experimental treatments, are depicted in Figure 1. The first is a region where the tie margin is large enough to prohibit or completely discourage any active competition. This specifically occurs when the cost of outbidding the other player by strictly more than the tie margin exceeds the marginal benefit of winning versus tying. Or rather, when $\delta \geq(1-\beta) v$ for $\beta \in[0,1)$. The unique equilibrium is then for players to bid zero with probability one and reap the value of tying. This is the only portion of the parameter space that has an equilibrium in pure strategies.

The second region consists of intermediate tie margins and every point in this region has a unique symmetric equilibrium 8 Moreover, for much of the second region (including the two experimental treatments that fall within this region), the equilibrium is also unique in the broader class of all Nash equilibria.$^{9}$ Here, players essentially randomize between going for the tie and going for the win. This is evident in that the equilibrium requires randomization over two disjoint intervals, as

\footnotetext{
${ }^{8}$ The second region is defined by $\delta \in[(1-\beta) v / 2,(1-\beta) v)$ if $\beta \in(0,1 / 2)$, and $\delta \in((1-$ $\beta) \beta v,(1-\beta) v)$ if $\beta \in[1 / 2,1)$.

${ }^{9}$ Asymmetric equilibria exist for $\delta \in[(1-\beta) v / 2,(1-2 \beta) v]$ and $\beta \in(0,1 / 3]$.
} 


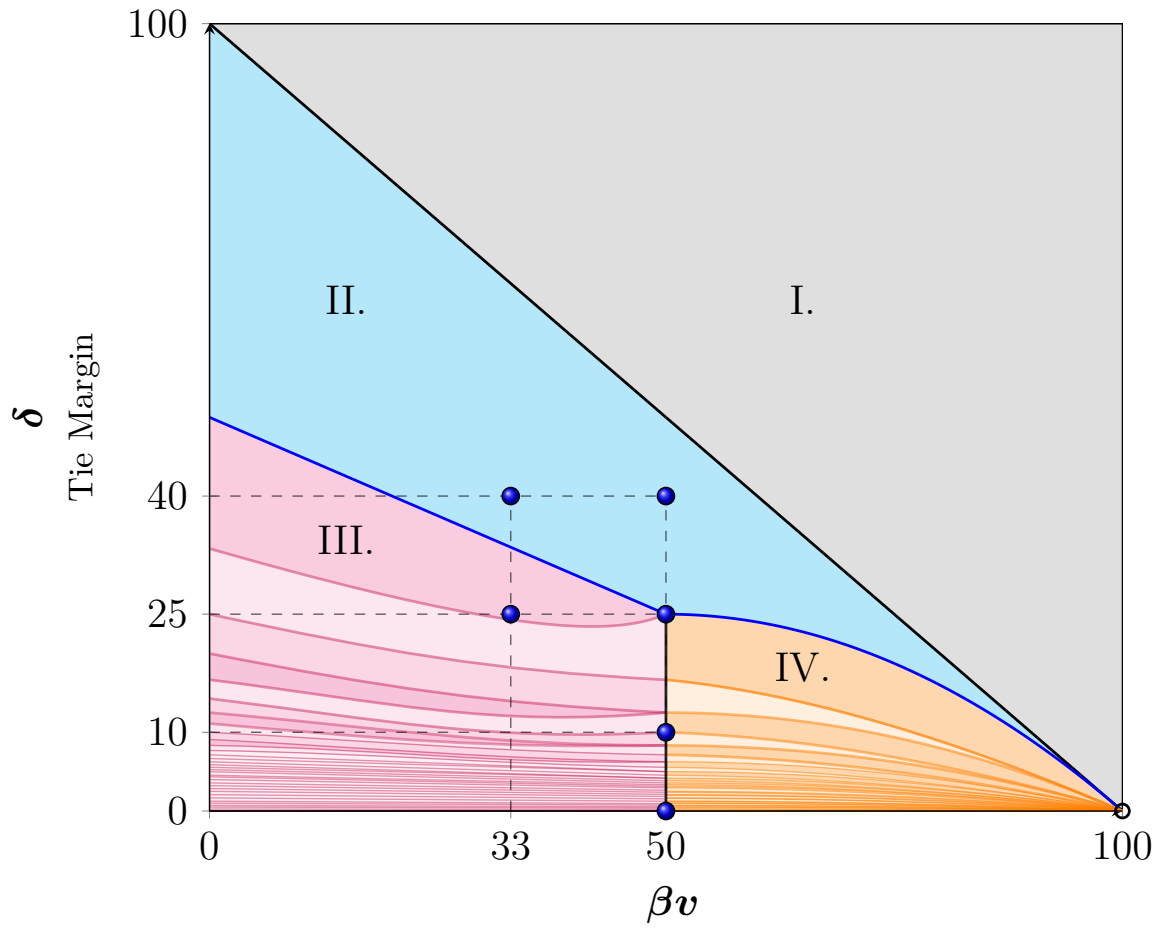

Prize for Tying

Figure 1: Parameter Space with $v=100$. The four principle regions are labeled with Roman numerals. Dots mark the six experimental treatments.

well as a mass point at zero (as depicted in panel (a) of Figure 22). The two intervals have the same length and are positioned exactly $\delta$ apart from each other; the upper interval beginning at $\delta$ and the lower interval beginning at zero.10 Thus a bid of zero ties both the other player's mass point at zero and their entire lower interval. Bids within the lower interval additionally tie a portion of the bids in the upper interval. Meanwhile, bids in the upper interval beat the mass point at zero and a portion of the lower interval, tying all remaining bids. For a player to be willing to incur the cost of bidding in the lower interval they must tie mass in the upper interval with a sufficiently high probability. Since $\beta v$ is the value of tying relative to losing, the unit cost of a bid is offset in expectation by a uniform density rate over the upper interval of $1 /(\beta v)$. Likewise, bids in the upper interval must beat a sufficient amount of mass in the lower interval, so a density rate of $1 /[(1-\beta) v]$ over the lower interval balances the value of winning relative to tying.

\footnotetext{
${ }^{10}$ Each interval has a length of $\beta v-[\delta \beta /(1-\beta)]$, with a uniform density rate of $1 /[(1-\beta) v]$ over the lower interval and $1 /(\beta v)$ over the upper. The remaining mass of $[\delta-(1-\beta) \beta v] /\left[(1-\beta)^{2} v\right]$ is at zero.
} 


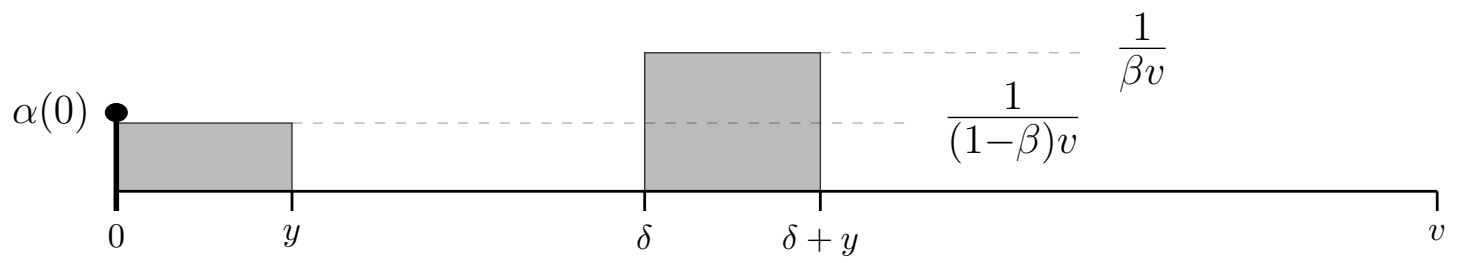

(a) Region II Example: One pair of intervals, plus a mass point at zero.

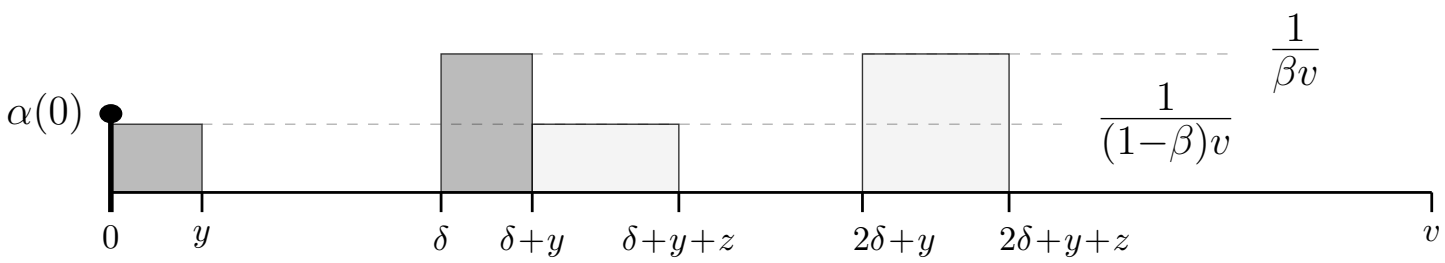

(b) Region III Example: Two pairs of intervals, plus a mass point at zero.

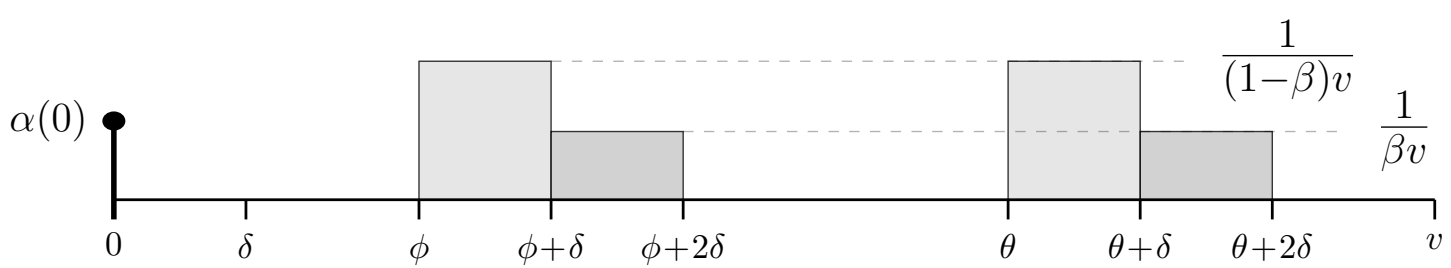

(c) Region IV Example: Two intervals of length-2 $\delta$, plus a mass point at zero.

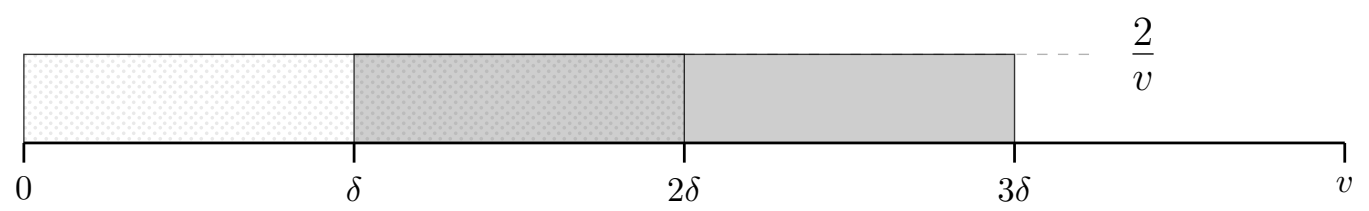

(d) Upper and lower bound of equilibria when $\beta=1 / 2$ and $\delta=v / 4$.

Figure 2: Density plots of equilibrium strategies. 
The third region addresses small tie margins and small tie prizes $(\beta<1 / 2)$, while small tie margins with large tie prizes $(\beta>1 / 2)$ are covered by the fourth region. Equilibrium in the third region is similar to the second, except that instead of one pair of intervals, there are multiple pairs of intervals. An example with two pairs of intervals is shown in panel (b) of Figure 2. The spacing of the intervals is such that players still either go for the tie or go for the win, but in finer partitions since the tie margin is smaller. Within each pair, the lower interval has a density rate of $1 /[(1-\beta) v]$, the upper has a rate of $1 /(\beta v)$, and the two intervals have the same length (although lengths can differ across pairs). Intervals within the first pair have lower bounds of zero and $\delta$. The second interval pair begins immediately after the first without any gap (i.e. the upper bound of the upper interval from the first pair is the lower bound of the lower interval from the second pair). The alternating pattern of gaps within interval pairs (with lower bounds spaced $\delta$ apart), but no gaps between interval pairs, continues for the remainder of the distribution. As the tie margin decreases, the equilibrium is comprised of successively more pairs of intervals so that as $\delta$ approaches zero, the equilibrium distribution converges to that of the standard all-pay auction. ${ }^{11}$ The growth in the number of interval pairs is depicted in Figure 1 by the numerous segments that divide the third region. The uppermost segment has two interval pairs, the next has three, then four, etc.

In the fourth region, with $\beta>1 / 2$, the marginal benefit of tying is greater than the marginal benefit of winning. The equilibrium structure therefore shifts somewhat as players place a greater emphasis on tying. The principal building block of an equilibrium here is an interval that is $2 \delta$ in length with a density rate of $1 /[(1-\beta) v]$ over the lower half and $1 /(\beta v)$ over the upper. Lower bounds of successive intervals are spaced at $\delta /[(1-\beta) \beta]$. Similar to the third region, the number of these intervals in an equilibrium increases as the tie margin decreases - ultimately converging to the equilibrium of the standard all-pay auction. Panel (c) of Figure 2 illustrates an equilibrium with two intervals of length- $2 \delta$.

The six parameter combinations that we experimentally examine typify many features of equilibria throughout the parameter space. In each case, we fix the winning prize $v$ at 100 francs (the currency of the experiment). Our baseline treatment is the standard all-pay auction with the prize split evenly in the event of a tie (i.e. $\beta v=50$

\footnotetext{
${ }^{11}$ The equilibrium in the standard all-pay auction is to randomize with a uniform density of $1 / v$ over the interval $[0, v]$. With $\delta>0$, there are always measurable subsets of $[0, v]$ that are not in the equilibrium support. But as $\delta$ decreases, these subsets become finer and are spread more evenly across the distribution. Balanced with the density rates of $1 /[(1-\beta) v]$ and $1 /(\beta v)$ over the intervals which are in the support, the average density over any fixed subset $[p, q] \subseteq[0, v]$ approaches $1 / v$.
} 
and $\delta=0$.) Although equilibrium in the standard all-pay auction is invariant to a host of tie-breaking rules, the typical assumption is that the expected value of a tie is one-half the value of winning. Our next three treatments maintain a tie prize of 50 while increasing the tie margin from 0 up to 10, 25, and 40. Theoretically, players become inactive once $\delta \geq(1-\beta) v$; or in this case, once the tie margin reaches 50 . So the tie margins of 10,25 , and 40 roughly divide the portion of the parameter space where players actively compete. With $\beta=1 / 2$, a tie margin of 10 straddles the third and fourth regions of the parameter space. It is a special point in that the limiting equilibrium is the same as $\beta$ approaches $1 / 2$ from above and from below. That is, the equilibrium of the third and fourth region coincide at this point. ${ }^{12}$ This equilibrium specifically entails a mass point at zero of 0.2 , and then randomization over the intervals $[20,40]$ and $[60,80]$ at the uniform rate of $1 / 50.13$

The tie margin of 25 takes center stage in the parameter space, lying squarely at the junction of the second, third, and fourth regions when $\beta=1 / 2$. Accordingly, it is also home to a plethora of equilibria, defined by two fundamental characteristics. The first is that each player uniformly randomizes over the interval $[25,50]$ at a density rate of $1 / 50$. The second is that for any fixed subset $[a, b] \subseteq[0,25]$, each player's total density over $[a, b] \cup[a+50, b+50]$ equals $(b-a) / 50 \sqrt{14}$ The precise distributions over $[0,25]$ and $[50,75]$ can potentially differ across players. Of this vast set of equilibria, the one that generates the lowest amount of revenue in expectation is the one where both players randomize over the interval $[0,50]$. The one that generates the highest entails both players randomizing over [25, 75]. These bookends, depicted in panel $(\mathrm{d})$ of Figure 2, are also limiting equilibria - the former

${ }^{12}$ The set of $\delta \in[0, v / 2]$ for which the equilibrium of the third and fourth region coincide at $\beta=1 / 2$ is a measure zero set. In the complement of that set, differing limits lead to a multiplicity of equilibria when $\beta=1 / 2$, including a spectrum of equilibria that roughly bridges the two limits.

${ }^{13}$ The pattern from the fourth region of randomizing over intervals of length- $2 \delta$ is clearly evident in this equilibrium. In the third region, when $\delta=10$ and $\beta$ is slightly less than $1 / 2$, players randomize over six pairs of intervals. However, in the limit as $\beta$ increases to $1 / 2$, the lengths of the intervals in the first, second, fourth, and fifth interval pairs approach zero, while the lengths of the intervals in the third and sixth pairs approach $\delta$. Thus $[20,40]$ is the third pair and $[60,80]$ is the sixth pair.

${ }^{14}$ The full set of equilibria also encompasses any compound or mixed distribution over a set of distributions satisfying these requirements. The first requirement of a density rate of $1 / 50$ over $[25,50]$ keeps players indifferent between any two bids in $[0,25]$ or $[50,75]$. For bids $p, q \in[0,25]$ such that $p<q$, the cost differential of $q-p$ is exactly offset by the added likelihood of tying bids in $[25+p, 25+q]$. For $p+50, q+50 \in[50,75]$, the cost differential is similarly compensated by an added likelihood of beating bids in $[25+p, 25+q]$. The second requirement maintains players' indifference between bids in $[25,50]$. A player will increase his bid in this interval so long as the additional bidding cost is offset by some combination of an added probability of winning rather than tying and an added probability of tying rather than losing. 
being reached as $\delta$ approaches 25 from above, and the latter as $\delta$ goes to 25 from below ${ }^{15}$ Importantly, the equilibrium with the highest revenue is a mean-preserving contraction of the equilibrium in the standard all-pay auction. It therefore leads to full rent dissipation of the winning prize.

Keeping the tie prize at 50, bids are much less aggressive when the tie margin increases to 40. Falling well within the second region of the parameter space, the unique equilibrium places $60 \%$ of the bidding mass at zero and evenly distributes the remaining mass over the intervals $[0,10]$ and $[40,50]$ at a rate of $1 / 50$. Each player's average expenditure is a mere 10 francs. With a high likelihood of tying, however, the expected payoff increases to 40 .

The final two treatments again consider the tie margins of 25 and 40, but with a change in the tie prize from 50 to 33 so that tying is now worth roughly one-third the value of winning (the equilibria in panels (a) and (b) of Figure 2 are drawn to scale for these last two treatments). One relevant question is whether players are more or less aggressive when the value of tying decreases. Theoretically, the tie margin is crucial for answering this question. For a tie margin of 40 , the equilibrium is quite similar whether the tie prize is 33 or 50 . Both cases lie within the second region of the parameter space. Yet, the higher marginal benefit of winning when the tie prize is 33 results in three substantial alterations to the equilibrium, making it more aggressive than when the tie prize is 50 . First, the mass point at zero is a third smaller (0.4 vs. 0.6); second, players randomize over wider intervals, $[0,13.3]$ and $[40,53.3]$ instead of $[0,10]$ and $[40,50]$; and third, the upper interval has roughly twice as much mass as the lower interval (density rates of $1 / 33$ and $1 / 67$, as opposed to $1 / 50$ over both intervals). The end result is that the smaller tie prize doubles a player's average bid in equilibrium - increasing it from 10 to 20.1 francs.

With a tie margin of 25 , however, decreasing the tie prize may instead decrease average bids. The treatment of $\beta v=33$ and $\delta=25$ is in the third region of the parameter space, and specifically falls within the area where players randomize over two pairs of intervals. In equilibrium, intervals in the lower pair have a length of 6.9 and intervals in the upper pair have a length of 11.1 (each rounded to one decimal place). So players randomize over [0, 6.9], [25, 31.9], [31.9, 43.0], and [56.9, 68.0] at alternating density rates of $1 / 67$ and $1 / 33$. Additionally, there is a mass point at zero of 0.19 . The average bid is then 33.3 , which is down a third from the average

\footnotetext{
${ }^{15} \mathrm{As} \delta$ approaches 25 from above, the length of each interval in panel (a) of Figure 2 goes to $\delta$ and the mass point goes to zero. Approaching 25 from below resembles panel (c) of Figure 2 but with one interval of length- $2 \delta$ instead of two. Again, the mass point goes to zero.
} 
bid of 50 in the equilibrium with the maximum dissipation for a tie prize of 50 .

\section{Experimental Design}

For each of our six treatments, we ran the experiment with 12 independent groups of six subjects, for a total of 432 subjects. Each group's composition remained fixed throughout the experiment, and we ran multiple groups simultaneously so that subjects did not know which of the other participants in the room were part of their group. Each session began with subjects reading a set of instructions on their computer and completing a 15 question comprehension quiz (a copy of the instructions, quiz, and screen shots from the experiment are in the appendix). The bulk of the quiz focused on attuning subjects to the range of potential outcomes by giving them several pairs of hypothetical bids and asking them to calculate their payoff in each case. To encourage a good faith attempt, we paid subjects $\$ 0.20$ for each correct answer.

The experiment consisted of 30 all-pay auctions with the specified tie margin and tie prize. Subjects were randomly and anonymously matched and re-matched with another member of their group of six for each all-pay auction. In each of the 30 periods, subjects were given an endowment of 120 francs to bid for a prize of 100 francs ${ }^{16}$ Bids could be any number between 0 and 120 inclusive, with up to one decimal place. At the end of each auction, the computer displayed the bids of the two players, the subject's reward (100 for winning, 0 for losing, and 50 or 33 for tying), and the resulting payoff (the endowment plus the reward, minus the subject's bid). Subjects were asked to write down their results at the end of each period on a record sheet ${ }^{17}$ At the conclusion of the experiment, subjects were privately paid in cash. Payments averaged $\$ 23.50$, with a maximum of $\$ 39.00$ and a minimum of $\$ 7.35$. Subjects also received $\$ 7.00$ for showing up on time and participating 18

\footnotetext{
${ }^{16}$ With the exception of Potters et al. (1998), all previous complete information all-pay auction experiments gave subjects a large one-time endowment at the start of the experiment, rather than a specific endowment for each period. Individual bidding observations are, however, arguably more independent in the absence of an inter-temporal budget constraint. Previous studies have also been concerned with making sufficient allowance for subjects to bid more than the value of the prize. In terms of an ex-ante per period budget, our budget allows subjects to bid more than in any other study except Ernst and Thöni (2013) (although they did not advertise it to their subjects, their software capped bids at $125 \%$ of the value of the prize).

${ }^{17}$ We thought that subjects would be more cognizant of their performance if they paused to write down their results rather than immediately submitting their bid for the next auction.

${ }^{18}$ Payments were based on the sum of payoffs in three randomly selected all-pay auctions at a rate of 20 francs to 1 US dollar. They also included earnings from correctly answered quiz questions and two risk preference lotteries which we conducted following the 30 all-pay auctions.
} 
The experiments were conducted at the Economic Science Institute, Chapman University, in a computer lab with partitions separating the computers for privacy. All participants were Chapman undergraduates and were recruited via email from all majors ${ }^{19}$ Sessions lasted approximately one hour. ${ }^{20}$

\section{Results}

We begin by examining the degree to which bidding patterns conform to equilibrium behavior, as well as identifying pertinent departures from it. Since all equilibria are in mixed strategies, we compare the bid and revenue distributions across treatments. A key focus is to provide a ranking of the treatments in terms of the revenue they generate. In other words, we want to know the conditions that lead to more or less aggressive bidding. We first compare the four treatments that have a tie prize of 50 . These treatments allow us to hone in on the role of the tie margin when changed in isolation. We then study the joint role of the tie margin and the tie prize by looking at changes in bidding behavior when the tie prize decreases from 50 to 33 for tie margins of 40 and 25 .

Figure 3 depicts the equilibrium bid and revenue cumulative distributions for the four treatments with a tie prize of 50 , as well as the corresponding distributions during the last ten periods of the experiment. ${ }^{21}$ The equilibrium bid distributions in the top-left panel were discussed earlier in Section 2. As a brief summary, the $(50,0)$ treatment is simply the standard all-pay auction in which players uniformly randomize over the interval $[0,100]$; the $(50,10)$ treatment has a mass point at zero of 0.2 , followed by uniform randomization over $[20,40]$ and $[60,80]$; the $(50,25)$ treatment has a continuum of equilibria, ranging from uniformly randomizing over $[0,50]$ on the low end to uniformly randomizing over $[25,75]$ on the high end; and the $(50,40)$ treatment has a mass point at zero of 0.6 with uniform randomization over $[0,10]$ and $[40,50]$.

Additionally, subjects completed a demographics survey at the end of the experiment, which had no bearing on their payment. We have decided to exclude the demographic information from our analysis since it is of secondary importance.

${ }^{19}$ Participants had to have previously consented to be in the subject pool, which contains roughly a third of the undergraduate student body. Since records are kept of the types of experiments that subjects have previously participated in, we elected to only recruit subjects with no past experience in contest related experiments.

${ }^{20}$ While subjects had a 30 minute time limit to complete the initial instructions and quiz, 15 minutes was typically sufficient.

${ }^{21}$ Although this figure depicts the last ten periods, there are similar patterns in other period blocks as well. Later on we discuss the time trend of bids and show statistical results that extend throughout the thirty periods of the experiment. 

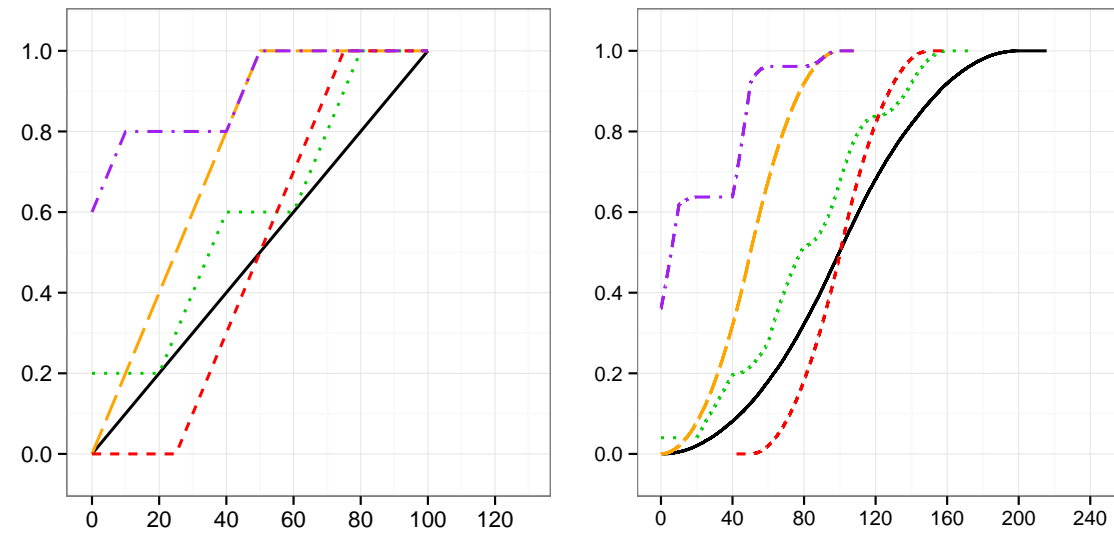

Tie Prize, Tie Margin
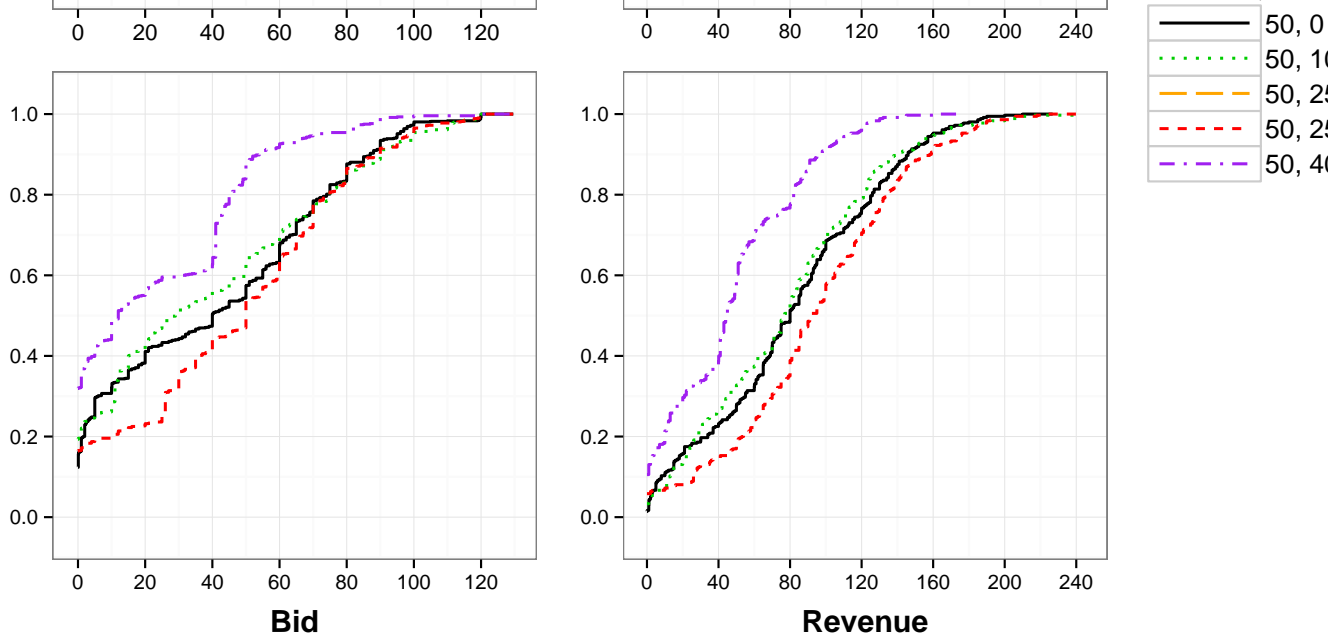

…... 50, 10

$--50,25$ (Low)

- - - - 50, 25 (High)

$-\cdot-\cdot-50,40$

Figure 3: Equilibrium (top row) and experimental (bottom row) bid and revenue distributions for treatments with a tie prize of 50. Data from last ten periods.

Qualitatively, many features of the equilibrium bidding distributions carry over to the experimental bidding distributions in the bottom-left panel of Figure 3. For instance, in the $(50,40)$ treatment, the basic pattern of a mass point at zero with randomization over a lower and upper interval is retained in the data - albeit with a smaller mass point at zero (0.32) and longer intervals (roughly 0 to 20 and 40 to $60)$. The dearth of bids between 25 and 40 is especially pronounced with a mere $1.7 \%$ of bids falling strictly between these values. In a similar fashion, bids are conspicuously absent in the $(50,10)$ and $(50,25)$ treatments immediately below their respective tie margins: the $(50,10)$ treatment has just $2.4 \%$ of bids strictly between 2 and 10 ; and in the $(50,25)$ treatment, only $1.4 \%$ of bids are strictly between 15 and 25 (7.2\% are strictly between 0 and 25$)$. 
Another noteworthy similarity between the experimental data and the equilibrium is the overall ranking of the distributions. The $(50,40)$ treatment is stochastically dominated by all other treatments; the $(50,10)$ treatment lies slightly above the $(50,0)$ treatment for bids between 20 and 60; and like the high-end equilibrium of the $(50,25)$ treatment, the experimental distribution of the $(50,25)$ treatment is well below the $(50,0)$ treatment throughout the lower range of bids. Unlike the high-end equilibrium, however, the experimental data for the $(50,25)$ treatment are actually able to keep pace and match the $(50,0)$ treatment over the high range of bids. The net result is that bids in the $(50,25)$ treatment tend to be more aggressive on average. The ranking of treatments by bids is naturally reflected in the ranking of treatments by revenue. The top-right and bottom-right panels of Figure 3 show the equilibrium and experimental revenue distributions. As was noted previously, the equilibrium of the $(50,0)$ treatment and the high-end equilibrium of the $(50,25)$ treatment are revenue equivalent. Both achieve full rent dissipation, or an expected revenue of $v=100$ (this is the upper bound for expected revenue over the entire parameter space). In the experiment, however, the $(50,25)$ treatment pulls ahead with an average revenue of 93.5 over the last ten periods, as compared to 80.5 in the $(50,0)$ treatment. The $(50,10)$ and $(50,40)$ treatments have averages of 77.3 and 47.1 .

The ranking of these four treatments in terms of revenue is statistically formalized in Table 1. The left-hand column specifies four pairwise comparisons of the different treatments (these are the alternative hypotheses). Dividing the data into blocks of ten periods, we employ three tests for each hypothesis. The first two are a Kolmogorov-Smirnov test and a Mann-Whitney U test where the level of observation is the revenue from a single all-pay auction with ties. Over ten periods, twelve groups, and three pairings per group in each period, these tests are based on 360 observations per treatment. Even though players are randomly and blindly matched each period, it is not uncommon for individual players to submit bids that are serially correlated across periods. The strict independence of the 360 revenue observations is therefore questionable. Our third test takes a highly conservative stance on independence by reducing the thirty revenue observations per group to a single observation: the group's average revenue over the block of ten periods. We then redo the Mann-Whitney $\mathrm{U}$ test with the twelve group-level observations per treatment. For each of these tests, Table 1 shows both the p-value and a measure of the effect size. The effect for the Kolmogorov-Smirnov test is simply the test statistic, or the maximal vertical difference of the revenue distribution of the second treatment (hypothesized to be stochastically dominated) minus the revenue distribution of the first treatment (hypothesized to be stochastically dominant). The effect size for the Mann-Whitney $U$ test is the likelihood that an observation taken at random from the first treatment is indeed larger than a randomly selected obser- 
Table 1: Revenue comparison of treatments with a tie prize of 50. Shows p-values of nonparametric tests with effect sizes in parentheses.

\begin{tabular}{llllll}
\hline & & & \multicolumn{3}{c}{ Periods } \\
\cline { 5 - 6 } Comparison & Test & Level & \multicolumn{1}{c}{$1-10$} & \multicolumn{1}{c}{$11-20$} & \multicolumn{1}{c}{$21-30$} \\
\hline$(50,25)>(50,0)$ & K-S & Bid $^{1}$ & $0.009(.114)^{3}$ & $0.007(.117)$ & $0.001(.144)$ \\
& MWW & Bid & $0.038(53.8 \%)^{4}$ & $0.023(54.3 \%)$ & $0.000(57.3 \%)$ \\
& MWW & Group $^{2}$ & $0.315(56.3 \%)$ & $0.136(63.5 \%)$ & $0.121(64.6 \%)$ \\
$(50,25)>(50,10)$ & K-S & Bid & $0.329(.056)$ & $0.049(.092)$ & $0.000(.167)$ \\
& MWW & Bid & $0.815(48.1 \%)$ & $0.050(53.5 \%)$ & $0.000(59.8 \%)$ \\
& MWW & Group & $0.724(43.1 \%)$ & $0.315(56.3 \%)$ & $0.057(69.4 \%)$ \\
$(50,0)>(50,10)$ & K-S & Bid & $1.000(.000)$ & $0.329(.056)$ & $0.294(.058)$ \\
& MWW & Bid & $0.993(44.7 \%)$ & $0.594(49.5 \%)$ & $0.156(52.2 \%)$ \\
& MWW & Group & $0.901(34.7 \%)$ & $0.665(45.1 \%)$ & $0.534(49.3 \%)$ \\
$(50,10)>(50,40)$ & K-S & Bid & $0.000(.269)$ & $0.000(.389)$ & $0.000(.336)$ \\
& MWW & Bid & $0.000(68.0 \%)$ & $0.000(75.1 \%)$ & $0.000(68.3 \%)$ \\
& MWW & Group & $0.006(79.9 \%)$ & $0.000(93.1 \%)$ & $0.000(94.4 \%)$ \\
\hline
\end{tabular}

${ }^{1}$ Individual bid pairs: 360 observations per treatment per period block.

${ }^{2}$ Average revenue for each group of six subjects: 12 observations per treatment per period block.

${ }^{3}$ Kolmogorov-Smirnov effect size: max vertical difference of CDFs (second treatment minus first).

${ }^{4}$ Mann-Whitney U test effect size: likelihood that a randomly selected observation from the first treatment is larger than a randomly selected observation from the second treatment.

vation from the second group.22

Based on the two tests conducted at the level of individual bid pairs, the $(50,25)$ treatment generates more revenue on average than the $(50,0)$ treatment. Moreover, the effect grows a bit stronger as the experiment continues from one period block to the next. Although standard significance levels are not quite reached with the limited group-level data (the p-value is down to 0.121 by periods $21-30$ ), a randomly selected group from the $(50,25)$ treatment will have a higher average revenue than its counterpart from the $(50,0)$ treatment nearly two-thirds of the time over the last ten periods. The $(50,25)$ and $(50,10)$ treatments are not statistically ranked during the first ten periods, but thereafter the $(50,25)$ treatment pulls increasingly

\footnotetext{
${ }^{22}$ If $n$ is the number of observations in each treatment, and $U$ is the statistic from the one-sided test, then the effect size is $1-\left(U / n^{2}\right)$, expressed as a percentage.
} 
ahead - even achieving a p-value of 0.057 with the group-level data over the last ten periods. The $(50,0)$ and $(50,10)$ treatments reveal no clear revenue ranking, with the exception that $(50,10)$ appears to be in the lead over the first ten periods. ${ }^{23}$ The firmest comparison in Table 1 is between $(50,10)$ and $(50,40)$. With every test and in all three period blocks, the $(50,40)$ treatment definitively generates less revenue. Although not shown, the same is true for pairwise comparisons of the other two treatments with $(50,40) \cdot{ }^{24}$ We summarize these findings as follows.

Result 1. For a tie prize of 50, revenue is not monotonic in the size of the tie margin; and contrary to theory, a tie margin of 0 (i.e. the standard all-pay auction) does not maximize revenue. A tie margin of 25 tends to generate more revenue than either 0 or 10, which in turn generate more revenue than a tie margin of 40 .

To understand why a tie margin of zero does not maximize revenue, we first note that, as stated in Result 4 below, average revenue in the $(50,0)$ treatment is consistent with past experimental studies of the two-player all-pay auction (Potters et al., 1998; Ernst and Thöni, 2013). So the revenue ranking is not a product of anomalous behavior in the all-pay auction. Two behavioral patterns are likely driving the $(50,25)$ treatment to surface to the top. First, as has been documented in other all-pay auction experiments (see the review by Dechenaux et al., 2015), the lower portion of the bidding distribution in the $(50,0)$ treatment is concave. Players tend to place either low or high bids, making mid-range bids doubly costly in that they are sure to lose against high bids, and low bids can be beat at a smaller cost.25 The result is that a full $41.1 \%$ of bids over the last ten periods are weakly below 20 , while only $6.7 \%$ are strictly between 20 and 40 . The second behavioral pattern counteracts the first. A tie margin of 25 acts almost like a participation fee, committing players either to action or inaction. And most of the would-be fence-sitters choose action 26

\footnotetext{
${ }^{23}$ One-sided Mann-Whitney U tests are symmetric, so the hypothesis that $(50,10)>(50,0)$ leads to p-values of 0.007 and 0.099 with the bid-pair and group-level data over the first ten periods. The one-sided Kolmogorov-Smirnov test, however, is not symmetric; the corresponding p-value is 0.058 with an effect size of 0.089 .

${ }^{24}$ For the comparisons of $(50,25)>(50,40)$ and $(50,0)>(50,40)$, the least significant test is with the group-level data over the first ten periods. Even then the p-values and effect sizes are $0.010(77.8 \%)$ and $0.019(75.0 \%)$.

${ }^{25}$ In other studies, the bifurcation into low and high bids is more dramatic so that the upper portion of the bidding distribution is actually convex. Klose and Sheremeta (2011) and Ernst and Thöni (2013) show that under the assumptions of prospect theory, the equilibrium bidding distribution is concave over the lower range of bids and convex over the upper range.

${ }^{26}$ Over the last ten periods, the percentage of bids that are strictly between 0 and 25 drops from $30.3 \%$ in the $(50,0)$ treatment to $7.2 \%$ in the $(50,25)$ treatment. Meanwhile, the mass point at zero in the $(50,25)$ treatment only increases by 4 percentage points over the $(50,0)$ treatment (16.4\% vs. $12.4 \%)$.
} 

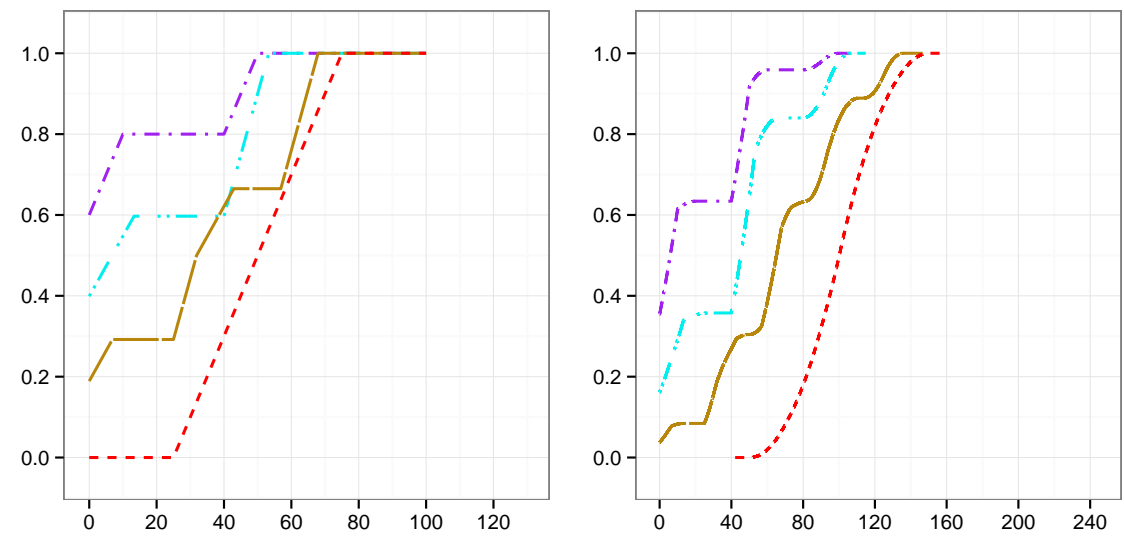

Tie Prize, Tie Margin
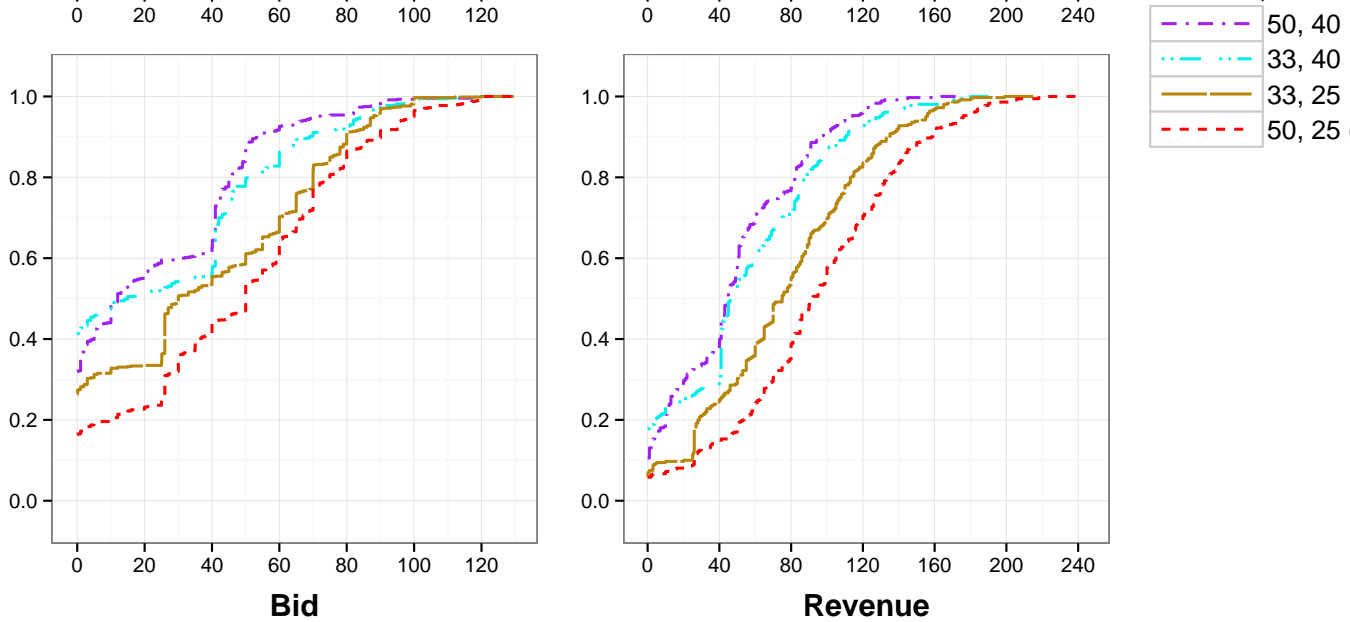

$\cdots-\cdots-33,40$

$-33,25$

- - - - 50, 25 (High)

Figure 4: Equilibrium (top row) and experimental (bottom row) bid and revenue distributions when tie prizes change from 50 to 33 . Data from last ten periods.

We now turn to the joint comparison of changes in both the tie prize and the tie margin. Since the tie margins of 25 and 40 have the highest and lowest average revenues of the four treatments with a tie prize of 50, we compare how behavior changes for these two tie margins when the tie prize decreases to 33. Figure 4 shows the theoretical and experimental bid and revenue distributions for these four treatments. Theoretically, as we saw in Section 2, decreasing the tie prize leads to a somewhat surprising prediction: bids become more aggressive with a tie margin of 40 , but less aggressive with a tie margin of 25 (compared to the high-end equilibrium of the $(50,25)$ treatment). This prediction is borne out in the experimental data. As can be seen in the bottom-left panel of Figure 4, the bidding distribution over the last ten periods for the $(50,25)$ treatment stochastically dominates the distribution for the $(33,25)$ treatment over the entire range of bids. The difference between the distributions can largely be attributed to a greater mass point at zero 
Table 2: Revenue comparison of treatments when the tie prize changes from 50 to 33. Shows p-values of nonparametric tests with effect sizes in parentheses.

\begin{tabular}{llllll}
\hline & & & \multicolumn{3}{c}{ Periods } \\
\cline { 5 - 6 } Comparison & Test & Level & \multicolumn{1}{c}{$1-10$} & $11-20$ & $21-30$ \\
\hline$(50,25)>(33,25)$ & K-S & Bid & $0.022(.103)$ & $0.000(.283)$ & $0.000(.183)$ \\
& MWW & Bid & $0.013(54.8 \%)$ & $0.000(66.6 \%)$ & $0.000(60.9 \%)$ \\
& MWW & Group & $0.221(59.7 \%)$ & $0.001(86.1 \%)$ & $0.038(71.5 \%)$ \\
$(33,25)>(33,40)$ & K-S & Bid & $0.000(.181)$ & $0.000(.183)$ & $0.000(.244)$ \\
& MWW & Bid & $0.000(59.0 \%)$ & $0.000(59.4 \%)$ & $0.000(63.7 \%)$ \\
& MWW & Group & $0.050(70.1 \%)$ & $0.044(70.8 \%)$ & $0.003(81.9 \%)$ \\
$(33,40)>(50,40)$ & K-S & Bid & $0.049(.092)$ & $0.033(.097)$ & $0.007(.117)$ \\
& MWW & Bid & $0.037(53.8 \%)$ & $0.029(54.1 \%)$ & $0.057(53.4 \%)$ \\
& MWW & Group & $0.149(62.8 \%)$ & $0.099(66.0 \%)$ & $0.239(59.0 \%)$ \\
\hline
\end{tabular}

Note: Levels of observation and effect sizes are defined in the footnotes of Table 1 .

in the $(33,25)$ treatment $(26.4 \%$ vs. $16.4 \%)$, as well as a greater mass of bids slightly above the tie margin of $25(11.9 \%$ vs. $5.7 \%$ for bids strictly between 25 and 27). Of the two treatments with a tie margin of 40 , the $(33,40)$ tends to have more aggressive bids; an exception, however, is that the $(50,40)$ treatment has a considerably smaller mass point at zero (31.9\% vs. $41.3 \%$; the distributions cross at 11). We also have a clear stochastic ordering between the $(33,25)$ and $(33,40)$ treatments. Similar to theory, these distributions nearly touch at a bid of forty. Otherwise, the $(33,25)$ treatment has decidedly more aggressive bids.

The ranking of the revenue distributions is consistent with the ranking of the bid distributions. As mentioned earlier, average revenue over the last ten periods for the $(50,25)$ and $(50,40)$ treatments is 93.5 and 47.1 francs respectively. The $(33,25)$ and $(33,40)$ treatments fall between at 75.2 and 54.2 francs. These four treatments are statistically ranked in terms of average revenue in Table 2. This table follows the same format as Table 1 but with the treatment comparisons of $(50,25)>(33,25)$, $(33,25)>(33,40)$, and $(33,40)>(50,40)$. By in large, these comparisons are supported in the different statistical tests. The comparison of $(50,25)>(33,25)$ has strong support, except in the group-level Mann-Whitney U test over the first ten periods. In fact, over periods 11-20, the Kolmogorov-Smirnov test statistic reaches 0.283 . Comparing $(33,25)$ and $(33,40)$, the least significant test is also the group-level Mann-Whitney $U$ test over the first ten periods, but this time with a p-value of only 0.050 . For $(33,40)>(50,40)$, the two tests based on individual 
bid pairs are significant at a $6 \%$ level or less over each of the ten-period blocks. The group-level Mann-Whitney U test also drops below the $10 \%$ level during periods 11-20. In summary, we have the following result:

Result 2. Both theoretically and in the lab, reducing the tie prize may either increase or decrease revenue. Whether revenue increases or decreases depends on the tie margin. Specifically, we can rank revenue across treatments as follows: $(50,25)>(33,25)>(33,40)>(50,40)$.

Within any given treatment, revenue does not stay at a constant level throughout the 30 periods of the experiment. Even still, the different treatments have similar ebbs and flows so that the revenue ranking across treatments remains fairly constant. Figure 5 plots the average revenue for each of the six treatments in three-period blocks. One pattern that is immediately evident is that revenue levels peak early on in the experiment. The first to peak is the $(50,40)$ treatment, which does so in the first three periods at an average revenue of 92.1 francs. It is closely followed by the $(33,40)$ treatment, whose revenue climbs slightly from the first to the second three-period block, peaking at 91.8 francs. The other treatments experience a more prolonged climb. The $(33,25)$ and the $(50,10)$ treatments peak in periods $7-9$ at 107.9 and 123.9 francs, while revenue in the $(50,0)$ and $(50,25)$ treatments steadily mounts until periods $10-12$, cresting at 110.9 and 114.8 francs respectively. Following the crest, revenue decreases at varying rates so that by periods 19-21, average revenue in each treatment has fallen below its corresponding level from periods $1-3$. Revenue finally levels off to an extent over the last three period blocks (periods 22-30).

Although the $(50,10)$ treatment initially emerges as the revenue leader, it suddenly drops from the lead as average revenue dives 18.2 francs from periods 10-12 to periods 13-15. Across treatments, this is the single largest change in average revenue from one period block to the next, leading to perhaps the most noticeable and dramatic alteration in the ranking of treatments by revenue. It also coincides with a sudden surge of players bidding zero ${ }^{27}$ The escalating revenue, persistent for so many periods, appears to hit a breaking point where a "shakeout" occurs in which several players opt out. Likewise, in the $(33,25)$ treatment, the rapid decline in revenue from periods $7-9$ to periods $13-15$ is also directly linked to a sizable increase in zero bids (rising from $12.5 \%$ to $28.7 \%$ ).

\footnotetext{
${ }^{27}$ During the first four three-period blocks in the $(50,10)$ treatment, the percentage of zero bids slowly increases from $7.4 \%$ to $10.6 \%$. It then jumps to $19.0 \%$ in periods $13-15$ and fluctuates between $17.6 \%$ and $20.4 \%$ thereafter.
} 


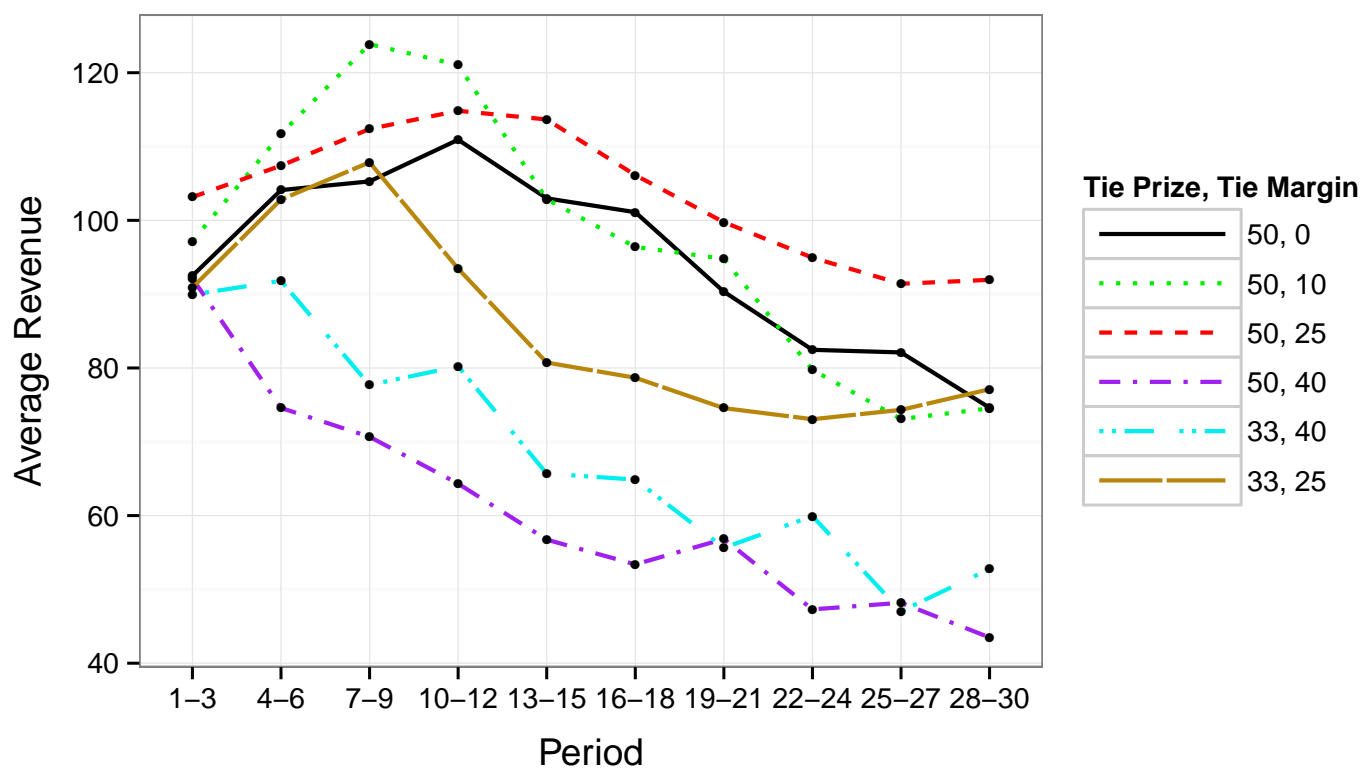

Figure 5: Average revenue over time.

In terms of revenue levels, a natural benchmark in the rent-seeking literature, and the touchstone measure since Tullock (1967), is the value of the winning prize $(v=100)$. The rent-seeking literature uses the term overdissipation if the sum of expenditures exceeds the value of the prize being contested and underdissipation if the sum is less than the prize value ${ }^{28}$ Aside from the two treatments with a tie margin of 40, average revenue extends above 100 in each treatment for at least two of the ten three-period blocks. The $(50,25)$ treatment makes it above 100 in nearly seven of the ten blocks (average revenue during periods 19-21 is 99.8). Thus we have a pattern of overdissipation when revenue peaks during the early periods and underdissipation thereafter. The magnitude of over- and underdissipation is fairly limited, however. The four treatments with tie margins less than 40 have dissipation rates that are bounded between $73 \%$ and $124 \%$ of the value of the prize throughout the experiment. We collate these observations from Figure 5 as follows:

Result 3. Across treatments, average revenue tends to escalate to a peak in the early periods of the experiment and then tapers off. Overdissipation often occurs in early periods with underdissipation occurring thereafter. Additionally, the ranking of treatments in terms of revenue remains fairly constant over the course of the experiment.

\footnotetext{
${ }^{28}$ In the all-pay auction with ties, the size of the purse is contingent on the outcome of the contest if the tie prize $\beta v \neq v / 2$. This potentially complicates the meaning of over- and underdissipation. For the discussion here, we use the traditional definitions, based solely on $v$ (i.e. the difference between the winning prize and the losing prize).
} 
Since the $(50,0)$ treatment is simply the standard all-pay auction, we can compare data from this treatment with past experimental studies. Potters et al. (1998) and Ernst and Thöni (2013) are especially relevant since they also address the two-player setting. ${ }^{29}$ In each of these studies, average bids are not statistically different from the theoretical prediction 30 Utilizing data from all periods as the other papers do, the same is true here. Based on the 12 group-level averages over all periods, a Wilcoxon signed-rank test cannot reject that the average bid is $50(\mathrm{p}$-value $=0.350){ }^{31}$ Across all periods, average revenue in Potters et al. is $99.3 \%$ of predicted revenue, $84.0 \%$ in Ernst and Thöni, and $94.6 \%$ here 32 Thus our revenue levels are in line with previous two-player all-pay auction studies ${ }^{33}$ Two appears to be a special number, however. With four or more players, revenue levels soar well above the value of the prize. 34

Looking at groups of four, eight, and twelve, Gneezy and Smorodinsky (2006) find that revenue can average as much as five times the value of the prize in the first period. Even after ten periods, the average remains between two and three times the value of the prize. In Davis and Reilly (1998), average revenue for a group of four reaches a similar magnitude at 2.34 times the prize value. ${ }^{35}$ Lugovskyy et al.

${ }^{29}$ Several of the design difference between these experiments were noted earlier on p. 4 fn. 6 .

${ }^{30}$ See Potters et al. (1998), p. 790; and Ernst and Thöni (2013), p.611, fn. 5. Ernst and Thöni do find that average bids are significantly higher than theory would predict in the treatment where subjects are not told anything about the outcome of each all-pay auction (average revenue is $119 \%$ of the value of the prize; see p. 614).

${ }^{31}$ Limiting the group-level averages to periods $10-12$, the height of the revenue peak in Figure 5 . there is some evidence that the average bid is greater than 50 ( $\mathrm{p}$-value $=0.055$ ). Conversely, the average bid is less than 50 over periods $19-30$ (p-value=0.011).

${ }^{32}$ For Potters et al., see Table 2, p. 788; for Ernst and Thöni, this comes from doubling the average bid of 42.0 (p. 611 ).

${ }^{33}$ Gelder and Kovenock (2015) has a treatment which conducts two-player all-pay auctions with fixed partners (instead of the random matching protocol used here and in Potters et al.). Revenue levels there are even lower. Over a 30 period horizon, average revenue is only $69.7 \%$ of the prize value. Also, with 35 independent pairings, a Wilcoxon signed-rank test shows that average bids are significantly less than the predicted value $(\mathrm{p}$-value $<0.001)$.

${ }^{34}$ The case of three players has received limited attention in the laboratory. Klose and Sheremeta (2011) have subjects play in groups of three for 30 periods with the composition of the group randomly changing each period. Average revenue over the 30 periods is $135.3 \%$ of the prize value (statistically above the value of the prize). Ernst and Thöni (2013) have two treatments that study groups of three: one in which the groups remain fixed over 10 periods and subjects observe the full history; and another where subjects are randomly assigned in each of 10 periods to groups of either two or three, but without any feedback from period to period (subjects are told the number of players in their group each period). These treatments yield average revenues of $110.7 \%$ and $123.6 \%$ of the prize value (the latter being statistically above the value of the prize). See Ernst and Thöni (2013), p.611, 614.

${ }^{35}$ Average revenue for a prize of 200 cents is 467.5 cents. See Davis and Reilly (1998), p. 101. 
(2010) conduct three experimental variations on groups of four (stranger matching, partner matching, and a domain shift of the strategy space). They also extend the experiment to 60 periods in hopes that average revenue will eventually fall to the value of the prize. This only occurs, however, in one of their treatments during the final ten periods ${ }^{36}$ Regardless of the number of players, theory predicts that average revenue in a symmetric all-pay auction should be the same as the prize value. In the two player case, multiple experiments support this prediction. Overdissipation is, however, the norm with four or more players. We therefore have the following result:

Result 4. Average revenue in the $(50,0)$ treatment is consistent with past experimental studies of the two-player all-pay auction. Additionally, the high degree of overdissipation that occurs in experiments with four or more players is not a salient feature of the two-player case.

The contrast between two and four or more players is likely connected to the knifeedge, winner-take-all nature of the all-pay auction. If players shun moderate bidseither going for the win or refraining from competing-overdissipation is likely if even two players submit aggressive bids. Avoiding overdissipation then becomes a coordination problem which compounds as the number of players increases. A parallel can be drawn to Bertrand price competition - another knife-edge, winner-take-all environment. Marginal cost pricing is expected to hold regardless of the number of players. Experimentally though, two is once again a special number. Fouraker and Siegel (1963) and Dufwenberg and Gneezy (2000) both find evidence to suggest that the Bertrand prediction is more accurate with three or more players than with two ${ }^{37}$ Players submitting bids above marginal cost must hope to be paired with

\footnotetext{
${ }^{36}$ It occurs in the treatment where the strategy space is shifted from a positive to a negative domain. In the other two treatments, average revenue falls from roughly 1.75 and 2.15 times the value of the prize in the first ten periods to 1.15 and 1.25 in the last ten periods. See Lugovskyy et al. (2010), Figure 2, p. 980.

${ }^{37}$ In one of the pioneering experiments of industrial organization, Fouraker and Siegel (1963, Chapter 10) compare Bertrand-like duopolies and triopolies under two information regimes (one in which players only know whether their price was the lowest, and another where all prices are revealed after each period). In each regime, triopolies quickly converge to marginal cost pricing. If the opponent's last price is not revealed, duopolies likewise have a tendency toward marginal cost pricing, but the convergence is not as quick or widespread as it is for triopolies. The move to marginal cost pricing is even less likely for duopolies that actually observe their opponent's last price (only one-third reach it after 14 periods). Dufwenberg and Gneezy (2000) examine Bertrand competition with groups of two, three, and four players. Similarly, average winning prices tend to be lower in groups of three or four players than with two players. Although winning prices approach marginal cost with three or four players, there is a considerable spread for the losing prices. Baye and Morgan (2004) show that the distribution of prices in Dufwenberg and Gneezy can reasonably be modeled in terms of bounded-rationality (the empirical distributions falling between an epsilon equilibrium and a quantal response equilibrium).
} 
players submitting even higher bids. With three or more players, however, there is a higher likelihood that at least one player submits a price at or near marginal cost - not necessarily that all players price near marginal cost.

\section{Conclusion}

We use a laboratory experiment to study strategic behavior in an all-pay auction in which a tie occurs unless one player outbids the other by strictly more than a given amount. We find that there is a non-monotonic relationship between how aggressively players bid and the size of both the margin required for victory and the value of tying relative to winning. Contrary to the theoretical prediction, we find that it is possible to generate more revenue on average than with the standard all-pay auction by introducing a moderately sized tie margin (one-quarter of the winning prize in our experiment). In competitions involving a winning prize that is potentially divisible between close contenders, using such a tie margin may be an advisable way to increase collective effort.

The study of ties has numerous extensions. Both our theoretical benchmark and our experiment are symmetric games with the value of winning, tying, and losing fixed across players. Asymmetries may arise, however, in terms of either the difference between the winning and losing prize or the difference between the value of tying and the value of losing. Within a political context, for instance, a status quo policy (which occurs in the event of a tie) may be closer to one party's ideal point than the other's. The two parties then have asymmetric incentives for tying versus winning. Questions of this nature can be examined theoretically, experimentally, and empirically. Our study of ties has also been limited to two players. Yet there are certainly contests with vast numbers of players where ties play a meaningful role. In bicycling, for example, a long stretch of riders are all awarded the same finishing time as long as the gap between any two successive riders is not sufficiently large. Contests may also involve incomplete information. Stong (2014) provides a partial characterization of equilibrium when the ratio of the tie prize to the winning prize is fixed across players, but players have privately known valuations of the winning prize. Behaviorally, the framing of the contest is no doubt another important consideration. Does winning represent a potential Pareto improvement or does it have more of a zero-sum nature where the loser essentially pays the winner? These and other extensions will lead to a fuller understanding of strategic behavior in the presence of ties. 


\section{References}

Amaldoss, W., Jain, S. (2002). David vs. Goliath: An analysis of symmetric mixedstrategy games and experimental evidence. Manage. Sci. 48(8), 972-991.

Baye, M.R., Kovenock, D., de Vries, C.G. (1994). The solution to the Tullock rentseeking game when $\mathrm{R}>2$ : Mixed-strategy equilibria and mean dissipation rates. Public Choice, 81(3-4), 363-380.

Baye, M.R., Kovenock D., de Vries C.G. (1996). The all-pay auction with complete information. Econ. Theory 8(2), 291-305.

Baye, M.R., Morgan, J. (2004). Price dispersion in the lab and on the internet: Theory and evidence. RAND J. Econ. 35(3), 449-466.

Blavatskyy, P.R. (2010). Contest success function with the possibility of a draw: Axiomatization. J. Math. Econ. 46(2), 267-276.

Bouckaert, J., Degryse, H., de Vries, C.G (1992). Veilingen waarbij iedereen betaalt en toch iets wint. Tijdschrift voor economie en management, 1992, 37(4), 375-393.

Che, Y.K., Gale, I.L. (1998). Caps on political lobbying. Amer. Econ. Rev., 643-651.

Chen, Z., Ong, D., Sheremeta, R.M. (2015). The gender difference in the value of winning. Econ. Lett., forthcoming.

Clark, D. J., Riis, C. (1998). Contest success functions: An extension. Econ. Theory, 11(1), 201-204.

Cohen, C., Sela, A. (2007). Contests with ties. BE J. Theor. Econ., 7(1).

Cohen, C., Shavit, T., Rosenboim, M. (2012). The over-weighting of unfair tie in all-pay contest: An experimental study. Int. J. Econ. Theory, 8(3), 301-311.

Davis, D.D., Reilly, R.J. (1998). Do too many cooks always spoil the stew? An experimental analysis of rent-seeking and the role of a strategic buyer. Public Choice, 95(1-2), 89-115.

Dechenaux, E., Kovenock, D., Sheremeta, R.M. (2014). A survey of experimental research on contests, all-pay auctions and tournaments. Exp. Econ., 1-61.

Dufwenberg, M., Gneezy, U. (2000). Price competition and market concentration: an experimental study. Int. J. Ind. Organ., 18(1), 7-22.

Eden, M. (2006). Optimal Ties in Contests. The Center for the Study of Rationality, Hebrew University, Jerusalem. Discussion Paper 430. 
Ernst, C., Thöni, C. (2013). Bimodal bidding in experimental all-pay auctions. Games, 4(4), 608-623.

Fehr, D., Schmid, J. (2011). Exclusion in the all-pay auction: An experimental investigation. WZB, Working Paper.

Fouraker, L.E., Siegel, S. (1963). Bargaining behavior. New York: McGraw-Hill.

Gelder, A., Kovenock D. (2015). Rent dissipation in two-player all-pay auctions. Unpublished manuscript.

Gelder, A., Kovenock D., Roberson B. (2015). All-pay auctions with ties. Chapman University, Working Paper.

Gneezy, U., Smorodinsky, R. (2006). All-pay auctions - an experimental study. J. Econ. Behav. Organ., 61(2), 255-275.

Hillman, A.L., Riley, J.G. (1989). Politically contestable rents and transfers. Econ. Polit. 1(1), 17-39.

Imhof, L., Kräkel, M. (2014). Tournaments with gaps. Econ. Lett. 122(2), 211-214.

Imhof, L., Kräkel, M. (2015). Ex-post unbalanced tournaments. RAND J. Econ. (forthcoming).

Jia, H. (2012). Contests with the probability of a draw: A stochastic foundation. Econ. Rec. 88(282), 391-406.

Klose, B., Sheremeta, R.M. (2011). Behavior in all-pay and winner-pay auctions with identity-dependent externalities. University of Zurich, Working Paper.

Konrad, K.A. and D. Kovenock (2014). Interest groups, influence activities and politicians with imperfect commitment. Max Planck Institute for Tax Law and Public Finance, unpublished manuscript.

Lazear, E. P., Rosen, S. (1981). Rank-order tournaments as optimum labor contracts. J. Polit. Econ., 89(5), 841-864.

Llorente-Saguer, A., Sheremeta, R.M., Szech, N. (2015). Experimental investigation of caps and tie-breaking rules in all-pay auctions. Queen Mary University of London, Unpublished manuscript.

Lugovskyy, V., Puzzello, D., Tucker, S. (2010). An experimental investigation of overdissipation in the all pay auction. Europ. Econ. Rev., 54(8), 974-997.

Nalebuff, B.J., Stiglitz, J.E. (1983). Prizes and incentives: towards a general theory of compensation and competition. Bell J. Econ., 21-43. 
Otsubo, H. (2013). Do campaign spending limits diminish competition? An experiment. Econ. Bull. 33(3), 2223-2234.

Potters, J., De Vries, C.G., Van Winden, F. (1998). An experimental examination of rational rent-seeking. Europ. J. Polit. Econ., 14(4), 783-800.

Rapoport, A., Amaldoss, W. (2000). Mixed strategies and iterative elimination of strongly dominated strategies: An experimental investigation of states of knowledge. J. Econ. Behav. Organ., 42(4), 483-521.

Rosen, S. (1986). Prizes and incentives in elimination tournaments. Amer. Econ. Rev., 701-715.

Stong, S. (2014). All-pay auctions with ties. In: Contests: Uncertainty and budgets. Univ. Iowa, PhD Thesis, 64-78.

Skaperdas, S. (1996). Contest success functions. Econ. Theory, 7(2), 283-290.

Szech, N. (2015). Tie-breaks and bid-caps in all-pay auctions. Games Econ. Behav., $92,138-149$

Tullock, G. (1967). The welfare costs of tariffs, monopolies, and theft. Econ. Inq., $5(3), 224-232$.

Tullock, G. (1980). Efficient rent seeking. In: Towards a theory of the rent-seeking society. Eds: Buchanan, J., Tollison, R., Tullock, G. College Station, TX: Texas A\&M University Press, 269-282.

Yildizparlak, A. (2013). Contests with ties and an application to football. Durham University, Working Paper.

Yildizparlak, A. (2015). Contests with draws. Durham University, Working Paper. 


\section{A. Experiment Instructions}

The (50, 0) treatment (i.e. the standard all-pay auction), as well as the two treatments with a tie prize of 33 used slightly different wording. Differences for the all-pay auction are noted in square brackets with the heading APA. Differences for the tie prize of 33 are set off with curly brackets and the heading Tie33.

\section{GENERAL INSTRUCTIONS}

This is an experiment in the economics of decision-making. Various research agencies have provided funds for this research. In addition to receiving $\$ 7.00$ for showing up on time and participating, you will have the opportunity to earn some money as part of this experiment. The exact amount you earn will be based on both your choices and the choices of the other participants. At the end of today's experiment, you will be paid in private and in cash.

You will have 30 minutes to read the instructions and complete a comprehension quiz. You do not need to rush. This should be more than enough time. We will proceed with the experiment at the end of 30 minutes or when everyone has finished the quiz, whichever comes first.

It is very important that you remain silent and do not look at other participants' work. If you have any questions, or need assistance of any kind, please raise your hand and an experimenter will come to you. If you talk, laugh, exclaim out loud, use your cell phone, etc., you will be asked to leave. We expect and appreciate your cooperation.

There are $\mathbf{3}$ parts to this experiment.

\section{PART 1}

This part of the experiment consists of $\mathbf{3 0}$ decision-making periods. Before the first period, you will be assigned to a set of six participants. This set will remain the same throughout the 30 periods, and you will not know the identity of the other five participants in your set.

Every period, you will be randomly and anonymously paired with another participant from your set. The participant you are paired with will randomly change from period to period (with an equal chance in any given period of being paired with any given participant in your set). Although you may be paired with the same participant multiple times throughout the experiment, you will not know if or when this happens.

The currency used in this experiment is francs. At the end of the experiment, francs will be converted to US Dollars at a rate of 20 francs to 1 US Dollar. 
In each period, you and the other participant will each be given an account of 120 francs. You may use your account to bid for a reward of 100 francs. Your bid may be any number of francs between $\mathbf{0}$ and 120 (including increments of 0.1).

You will receive the complete reward of 100 francs if your bid exceeds the bid of the other participant by strictly more than 25 francs. [APA: if your bid is larger than the other participant's bid.] For example, if you bid 60 francs while the other participant bids 15 francs then the computer will assign the complete reward of 100 francs to you and the other participant will receive no reward.

The other participant will receive the reward if his/her bid exceeds your bid by strictly more than 25 francs. [APA: if his/her bid is larger than your bid.] For example, if you bid 23 francs while the other participant bids 72 francs then the computer will assign the complete reward of 100 francs to the other participant and you will receive no reward.

If neither bid exceeds the other by strictly more than 25 francs, [APA: If a tie occurs] then you and the other participant will each receive half of the reward (50 francs) \{Tie33: will each receive 33 francs\}. For example, if you bid 40 francs while the other participant bids 45 francs [APA: if you bid 45 francs and the other participant also bids 45 francs,] then the computer will split the reward and assign 50 francs to you and 50 francs to the other participant \{Tie33: the computer will assign a reward of 33 francs to you and 33 francs to the other participant .

After both participants have made their bids, your earnings for the period will be calculated. Regardless of who receives the reward or whether it is split \{Tie33: or the size of the reward\}, each participant will have to pay his/her own bid. Thus, your earnings will be calculated in the following way:

$$
\text { Earnings }=\text { Account }+ \text { Size of Reward }- \text { Your Bid }
$$

More specifically, if you receive the complete reward:

$$
\text { Earnings }=120+100-\text { Your Bid }
$$

If you receive no reward:

$$
\text { Earnings }=120+0-\text { Your Bid }
$$

If you split the reward \{Tie33: If your bid is within 25 of the other participant's bid\}:

$$
\text { Earnings }=120+50-\text { Your Bid }
$$

At the end of each period the outcome screen will report your bid, the other participant's bid, the size of the reward you received, and your earnings for the period.

Please record the results for the period on your Record Sheet under the appropriate heading. 


\section{PAYMENT}

We will randomly select 3 out of the 30 periods for payment at the end of the experiment. Each period is equally likely to be selected for payment. Your earnings in these 3 periods will be converted from francs to US Dollars $(20$ francs $=1$ US Dollar), and you will be paid the sum of your earnings in these 3 periods.

\section{EXAMPLES}

Example 1: Assume that you bid 6 francs and the other participant bids 50 francs. The computer will then assign the reward of 100 francs to the other participant and 0 francs to you, since the other participant's bid exceeds your bid by strictly more than 25 francs $(50-6=44>25)$. [APA: Since the other participant's bid was larger than your bid, the computer will assign the reward of 100 francs to the other participant and 0 francs to you.] As a result, your earnings equal $120+0-6=$ 114 francs, since you did not receive the reward and your bid was 6 francs. The other participant's earnings equal $120+100-50=170$ francs, since the reward was 100 francs and the other participant's bid was 50 francs.

Example 2: Assume that you bid 25 francs and the other participant bids 20 francs. Therefore, the computer will split the reward of 100 francs between you and the other participant, since your bid is within 25 francs of the other participant's bid (that is, $25-20=5 \leq 25$ ). Each of you will receive a split reward of 50 francs. [APA: The computer will assign the reward of 100 francs to you since your bid was larger than the other participant's bid.] \{Tie33: Since your bid is within 25 francs of the other participant's bid (that is, $25-20=5 \leq 25$ ), then you will each receive a reward of 33 francs. $\}$ As a result, your earnings equal $120+50-25=145$ [APA: $120+100-25=195]\{$ Tie33: $120+33-25=128\}$ francs, since you received the reward of 50 [APA: 100] \{Tie33: 33 \} francs and your bid was 25 francs. The other participant's earnings equal $120+50-20=150$ [APA: $120+0-20=$ 100] $\{$ Tie33: $120+33-20=133\}$ francs, since the other participant received the reward of 50 \{Tie33: a reward of 33 \} francs and the other participant's bid was 20 francs. [APA: since the other participant bid 20 francs and did not receive the reward.]

\section{IMPORTANT NOTES}

You will not be told which of the participants in this room are matched with you. You will receive the reward of 100 francs if your bid exceeds the bid of the other participant by strictly more than 25 francs. [APA: if your bid is larger than the other participant's bid.] The other participant will receive the reward if his/her bid exceeds your bid by strictly more than 25 francs. [APA: if his/her bid is larger than 
your bid.] If neither bid exceeds the other by strictly more than 25 francs, [APA: If there is a tie,] then you and the other participant will split the reward and each receive 50 francs \{Tie33: will each receive a reward of 33 francs . Regardless of who receives a reward or the size of the reward, each participant will have to pay his/her own bid.

At the end of the experiment we will randomly select 3 out of 30 periods for payment and will convert your earnings to US Dollars. You will be paid the sum of your earnings from these 3 periods.

\section{Are there any questions?}

Before beginning the experiment, we ask that you complete 15 quiz questions. For each correct answer you will be paid $\$ \mathbf{0 . 2 0}$. Remember, you have 30 minutes to complete both the instructions and the quiz. Only questions answered within the 30 minute time period are eligible for payment. You may begin the quiz now.

Subjects were able to review the instructions while answering the quiz questions. Quiz answers were displayed after subjects answered each question.

\section{Quiz 1}

True or False: You will be paired with the same participant for all 30 periods of the experiment. (Write True or False in the space below.)

ANSWER: False. After each period, you will randomly be paired with another partner.

\section{Quiz 2-15}

Suppose that you bid $<$ Own Bid $>$ francs and the other participant bids $<$ Other Bid $>$ francs. How many francs would you receive from this portion of the experiment if it was selected for payment?

You can access a calculator by clicking the calculator icon at the bottom right (next to the Submit button).

Table A.1: Bidding values for the quiz questions:

\begin{tabular}{lrrrrrrrrrrrrrr}
\hline Quiz Number & 2 & 3 & 4 & 5 & 6 & 7 & 8 & 9 & 10 & 11 & 12 & 13 & 14 & 15 \\
\hline Own Bid & 51 & 77 & 18 & 60 & 5 & 28 & 42 & 95 & 0 & 46 & 64 & 37 & 84 & 21 \\
Other Bid & 95 & 7 & 105 & $* 39$ & 0 & 29 & 3 & 55 & 42 & 45 & 39 & 6 & 94 & 70 \\
\hline
\end{tabular}

*60 in standard all-pay auction treatment. 
Example of a quiz answer:

ANSWER: Since your bid was more than 25 francs greater than your partner's bid $(<$ Own $\mathrm{Bid}>-<$ Other $\mathrm{Bid}>=$ difference $>25)$, you receive the reward of 100 francs. Since you must pay your bid, your earnings equal $120+100-<$ Own Bid $>$ $=<$ earnings $>$.

Following the quiz:

Please click the Start button. We need everyone to click the Start button before we can begin PART 1 of the experiment. The instructions will remain on your screen until the experiment begins. If you have any questions, please raise your hand and an experimenter will come by to answer them.

\section{PART 2}

For the next part of the experiment, you will be given a set of 20 choices. You will be asked to choose between receiving $\$ \mathbf{1}$ for sure (Option A) and receiving $\$ 3$ with some probability and nothing otherwise (Option B). The probability of winning $\$ 3$ in Option B varies across the 20 choices. You should think of each choice as a separate decision that you need to make.

\section{PAYMENT}

At the end of the experiment, a spinner with the numbers 1 through 20 will appear on your screen. The spinner will randomly select one of your 20 choices for payment. Each choice is equally likely to be selected. Your payment for the selected choice will then depend on whether you chose Option A or Option B.

If you chose Option $\mathrm{A}$, you will receive $\$ 1$.

If you chose Option B, the spinner will randomly select another number between 1 and 20 (again, each number is equally likely to be selected). The result of that spin will determine whether you receive $\$ 3$ or $\$ 0$.

\section{Are there any questions?}

Please click the Start button. We need everyone to click the Start button before we can begin PART 2 of the experiment. The instructions will remain on your screen until the experiment begins. If you have any questions, please raise your hand and an experimenter will come by to answer them.

\section{PART 3}

You will again be given a set of 20 choices. Option $A$ is to receive $\$ \mathbf{0 . 0 0}$ for sure. Option B is to receive $\$ \mathbf{5 . 0 0}$ with one-half probability or lose between $\$ \mathbf{0 . 5 0}$ and $\$ \mathbf{1 0 . 0 0}$ with one-half probability. The exact amount you would lose in Option B 
varies across the 20 choices. You should think of each choice as a separate decision that you need to make.

\section{PAYMENT}

At the end of the experiment, a spinner with the numbers 1 through 20 will appear on your screen. The spinner will randomly select one of your 20 choices for payment. Each choice is equally likely to be selected. Your payment for the selected choice will then depend on whether you chose Option A or Option B.

If you chose Option $\mathrm{A}$, you will receive $\$ 0.00$.

If you chose Option B, the spinner will randomly select another number between 1 and 20 (again, each number is equally likely to be selected). The result of that spin will determine whether you receive $\$ 5.00$ or lose the specified amount (between $\$ 0.50$ and $\$ 10.00)$.

Any money that you lose will be deducted from your other earnings in this experiment. You are, however, guaranteed $\$ 7.00$ for showing up on time and participating.

\section{Are there any questions?}

Please click the Start button. We need everyone to click the Start button before we can begin PART 3 of the experiment. The instructions will remain on your screen until the experiment begins. If you have any questions, please raise your hand and an experimenter will come by to answer them.

Subjects were given the following demographics survey at the end of the experiment.

1. What is your age? [Integer response; default $=18$ ]

2. What is your gender? [(A) Female, (B) Male]

3. What is your primary racial/ethnic group? [(A) Asian, (B) Black, (C) Caucasian, (D) Hispanic, (E) Other]

4. What is the approximate annual household income of your family? (For this question, the definition of family is the parent(s) or guardian(s) with whom you primarily resided before coming to Chapman.) [(A) Less than $\$ 30,000$, (B) Between $\$ 30,000$ and $\$ 59,000$, (C) Between $\$ 60,000$ and $\$ 89,000$, (D) Between $\$ 90,000$ and $\$ 149,000$, (E) Between $\$ 150,000$ and $\$ 250,000,(\mathrm{~F})$ More than $\$ 250,000]$

5. Do you personally own any financial instruments, such as stocks, bonds, mutual funds, money market funds, etc.? [(A) Yes, (B) No]

6. How many credit cards do you have? [Integer response; default $=0$ ] 
7. How many hours did you spend on schoolwork outside of class time last week? This includes time spent reading, writing assignments, studying for tests, completing problem sets, etc. [(A) Less than 10 hours, (B) 10 to 19 hours, (C) 20 to 29 hours, (D) 30 to 39 hours, (E) 40 hours or more]

8. How many hours per week do you work? [(A) Less than 5 hours, (B) 5 to 9 hours, (C) 10 to 19 hours, (D) 20 to 29 hours, (E) 30 hours or more]

9. What is your major? [(A) Business and Economics, (B) Political Science and Law, (C) Engineering and Computer Sciences, (D) Math and Science, (E) Humanities and Film, (F) Other]

10. What year are you at the university? [Integer response; default $=1$ ]

11. Politically, do you consider yourself to be: [(A) Very liberal, (B) Somewhat liberal, (C) Neutral, (D) Somewhat conservative, (E) Very conservative]

12. What was your overall score on the SAT out of 2400? (Write NA if not applicable.) [Free response]

13. What was your overall score on the SAT out of 1600 ? (Write NA if not applicable.) [Free response]

14. What was your composite score on the ACT? (Write NA if not applicable.) [Free response]

15. Which statement best describes your religious beliefs? [(A) Not at all religious, (B) Not very religious, (C) Somewhat religious, (D) Religious, (E) Very religious]

16. What best describes your religious affiliation? [(A) Protestant, (B) Catholic, (C) Jewish, (D) Muslim, (E) Atheist, (F) Other]

17. How many Business and Economics classes have you taken so far (including those you are currently taking)? [Integer response; default $=0$ ]

18. How many competitive sports have you played (including ones you now play)? [Integer response; default $=0$ ]

19. How often do you purchase lottery tickets? [(A) At least weekly, (B) At least once per month, (C) At least once every 6 months, (D) At least once per year, (E) Never or less than once per year]

20. Evaluate the following statement: "When I play games for enjoyment, winning is very important to me." [(A) I strongly disagree, (B) I disagree, (C) I neither agree nor disagree, (D) I agree, (E) I strongly agree] 


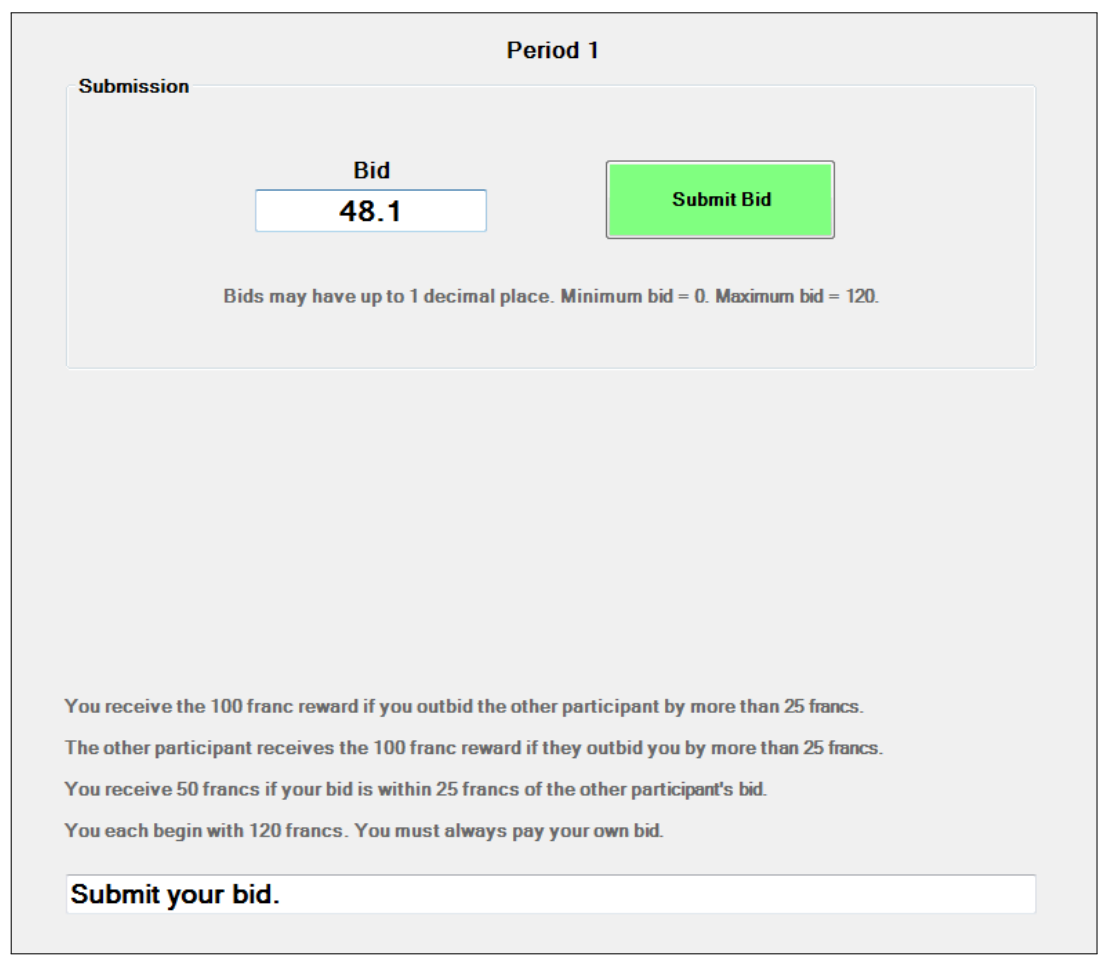

Figure A.1: Bid submission screen.

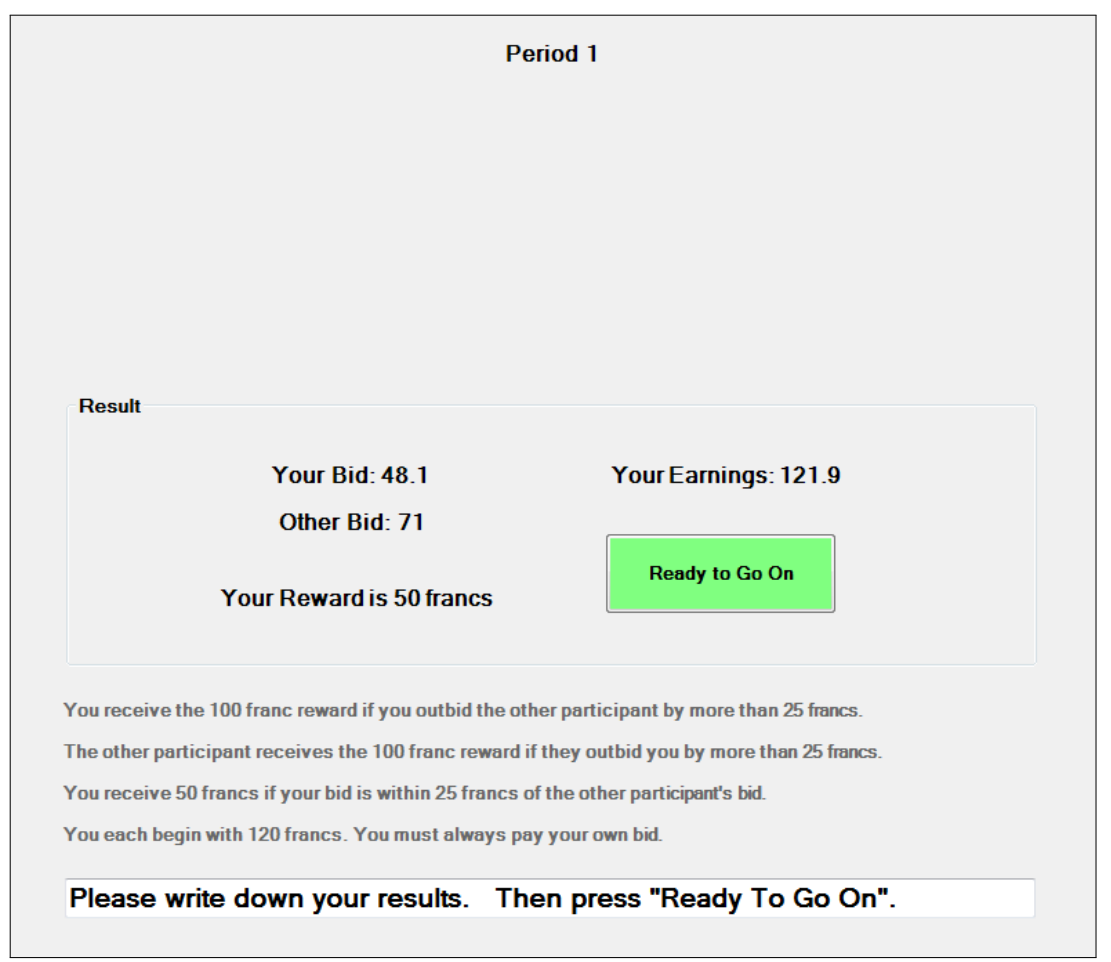

Figure A.2: Result screen. 


\section{Record Sheet}

\begin{tabular}{|c|c|c|c|c|}
\hline Period & Your Bid & Other Bid & Reward & Earnings \\
\hline 1 & & & & \\
\hline 2 & & & & \\
\hline 3 & & & & \\
\hline 4 & & & & \\
\hline 5 & & & & \\
\hline 6 & & & & \\
\hline 7 & & & & \\
\hline 8 & & & & \\
\hline 9 & & & & \\
\hline 10 & & & & \\
\hline 11 & & & & \\
\hline 12 & & & & \\
\hline 13 & & & & \\
\hline 14 & & & & \\
\hline 15 & & & & \\
\hline 16 & & & & \\
\hline 17 & & & & \\
\hline 18 & & & & \\
\hline 19 & & & & \\
\hline 20 & & & & \\
\hline 21 & & & & \\
\hline 22 & & & & \\
\hline 23 & & & & \\
\hline 24 & & & & \\
\hline 25 & & & & \\
\hline 26 & & & & \\
\hline 27 & & & & \\
\hline 28 & & & & \\
\hline 29 & & & & \\
\hline 30 & & & & \\
\hline
\end{tabular}

